\title{
有功賞受賞講演
}

\section{A Generation of Investigations of \\ Rheology and Structure Development in Polymer Processing: A Personal View}

by

James Lindsay White

Polymer Engineering Center, University of Akron

Akron, Ohio 44325, USA

（原稿受理：1984年11月 5 日）

\begin{abstract}
We present a critical review on research during the last generation on flow phenomena and structure development occurring in polymer processing operations. This is carried out using the methods of rheology and rheo-optics. We begin with a critical discussion of the rheological behavior of bulk polymer systems including flexible chain and liquid crystalline polymers as well as particle filled compounds. Experimental studies and theoretical models are considered. The characterization of molecular orientation is then carefully considered. Advances in process technology are reviewed and application to a range of processing operations including extrusion through dies, melt spinning, film extrusion, injection and blow molding and two phase melt flow including mixing are then critically discussed.
\end{abstract}

\section{INTRODUCTION AND}

\section{HISTORICAL REMAKS}

Rheology and rheo-optics provide a unique basis for understanding the phenomena occurring in polymer processing operations and structure development in fabrication parts. During the past generation there has been an enormous development of activity in this area which has considerably increased our understanding of polymer processing. In this paper I will attempt to present a general broad overview of these developments, but it is necessarily a personalized perspective emphasizing what I have considered to be important areas and thus those topics I have concentrated my activities on.

Both rheology and rheo-optics effectively date to the 19th century work of James Clerk Maxwell. ${ }^{1)}{ }^{2)}$ Rheo-optics is older with Maxwell's hypothesis of the Photoelastic Law between birefringence and stress ${ }^{1)}$ dating to 1853 . He later presented the first description of flow birefringence in polymer solutions ${ }^{3)}$. Maxwell's differential viscoelastic model for complex materials was published in $1867^{2)}$. The first careful rheological studies of complex materials was Schwedoff's) ${ }^{4}$ (6) investigations of gelatin suspensions which appeared in 1890. The subject and popularization of rheology itself were largely developed and organized by Bingham ${ }^{7)}$ in the 1920 's. Modern rheo-optics of polymers effectively dates to the 1940 s with Kuhn and Grun's ${ }^{8)}$ and Treloar's ${ }^{9)}$ establishment of the linear-relationship between birefringence and stress for a network of flexiblie chains and the latter studies of the crystallization of natural rubber. ${ }^{9), 10)}$ The Hermans' orientation factor quantifying uniaxial orientation effectively dates from the same period. ${ }^{11) \sim 13)}$

The perspective of rheology being used to investigate polymer processing problems dates to the $1920 \mathrm{~s}^{14) \sim 16)}$ but becomes explicitly clear in the 1930s with the publications of Mooney ${ }^{17) ~ 19)}$ and Dillon ${ }^{20), 21)}$ who sought to apply rheology to interpret rubber processing behavior. These studies saw careful rheolcgical characterization ${ }^{19)}$, investigation of the wall slip boundary condition $^{17)}$, analysis of flow in processing operations ${ }^{20)}$ and the development processability measurement techniques. ${ }^{14), 15), 18), 21)}$ 
The development of structured polymer products such as fibers and films did not begin until the 1940s and a generation was to pass before processing induced structure studies would be discussed.

In the $1950 \mathrm{~s}$ polymer melt processing operations were qualitatively analyzed with isothermal Newtonian models. The problem of structure (crystallization, orientation) development during processing had been realized by this period, but methods of representation of this structure and quantitatively relating it to processing were either unknown or went unrecognized. The monographs of Bernhardt ${ }^{22)}$ and McKelvey ${ }^{23)}$ published in this period represent this perspective.

\section{RHEOLOGICAL CHARACTERIZATION OF COMPLEX MATERIALS}

\section{General}

Any beginning to understanding the flow behavior of materials must be with their rheological characterization. The kinematics of flow of different processing operations varies significantly. Fluid materials generally adhere to metal surfaces so the flow of polymer systems in dies, molds and the metering regions of extruder screws are largely shearing in character i.e. where

$$
\boldsymbol{v}=v_{1}\left(x_{2}\right) \boldsymbol{e}_{1}+0 \boldsymbol{e}_{2}+0 \boldsymbol{e}_{3}
$$

In post die flows, polymer melts are not in contact with metal surfaces but are deformed in the air as filaments on shells/ membranes subjected to applied forces. Such flows are elongational in nature and the velocity field may be represented as

$$
\boldsymbol{v}=v_{1}\left(x_{1}\right) \boldsymbol{e}_{1}+v_{2}\left(x_{2}\right) \boldsymbol{e}_{2}+v_{3}\left(x_{3}\right) \boldsymbol{e}_{3}
$$

For uniaxial extension which includes melt spinning of fibers we have (for incompressible fluids)

$$
\frac{\partial v_{2}}{\partial x_{2}}=\frac{\partial v_{3}}{\partial x_{3}}=-\frac{1}{2} \frac{\partial v_{1}}{\partial x_{1}}
$$

For equal biaxial extension where ' 1 ' and ' 2 ' are the directions of stretch

$$
\frac{\partial v_{1}}{\partial x_{1}}=\frac{\partial v_{2}}{\partial x_{2}}=-\frac{1}{2} \frac{\partial v_{3}}{\partial x_{3}}
$$

The early experimental rheologists such as Schwedoff and Bingham as well as the industrial rheologists, Mooney and Dillon, investigated only shearing flows. The study of elongational flows of the type defined in Eq. (4a) were initiated in the 1960s by Ballman ${ }^{24)}$, Cogswell ${ }^{25)}$, Meissner ${ }^{26)}$ and Vinogradov and his coworkers ${ }^{27)}$ using a range of different instruments which applied either constant elongation rate or tensile stress. Shortly thereafter Denson and his colleagues ${ }^{28)}$,29) initiated basic measurements of biaxial and planar extensional flows with constant elongation rates

.Among steady flows only shear and uniaxial extension have received significant attention in the literature and we will confine our attention to these two classes of responses.
In shear flows defined by Eq. (1), one seeks to measure sheaing stresses $\sigma_{12}$ and principal and second normal stress differences $N_{1}$ and $N_{2}$ and their associated rheological coefficients defined by

$$
\begin{aligned}
& \sigma_{12}=\eta \dot{\gamma} \\
& \sigma_{11}-\sigma_{22}=N_{1}=\psi_{1} \dot{\gamma}^{2} \\
& \sigma_{22}-\sigma_{33}=N_{2}=\psi_{2} \dot{\gamma}^{2}
\end{aligned}
$$

whəre $\eta, \psi_{1}$ and $\psi_{2}$ are the shear viscosity and principal and second normal stress difference coefficients. In uniaxial extension defined by Eqs. (2) and (3), one seeks to measure an elongationl viscosity $\chi$ defined by

$$
\sigma_{11}=\sigma_{11}-\sigma_{22}=\chi \frac{\mathrm{d} v_{1}}{\mathrm{~d} x_{1}}
$$

In biaxial and planar extensional flows, one similarly defines biaxial $\chi_{B}$ and planar $\chi_{p}$ elongational viscosities.

\section{Molten Flexible Chain Polymers}

The behavior of polymer melts with flexible chains in steady shear flow has long been understood in qualitative terms, though it it only since about 1970 that extensive investigations have appeared in the literature. The shear viscosity function is a constant $\eta_{0}$ at low shear rates and decreases with increasing rate of shear. It was found in the $1940 \mathrm{~s}$ that $\eta_{0}$ increases with about the 3.4 power of molecular weight (roughly weight average $M_{w}$ ) in materials consisting of linear polymer chains. ${ }^{30)}$ The shear rate dependence of viscosity function $\eta(\dot{\gamma})$ depends upon the breadth of the molecular weight distribution. This first became clear in the 1960 s when plots of $\eta / \eta_{0}$ as a function of shear stress $\left(\sigma_{12}=\eta \dot{\gamma}\right)^{31)}$ or some arbitrary relaxation time multiplied by shear rate $\left(\tau_{G} \dot{\gamma}\right)^{32), 33)}$ appeared. These plots were roughly independent of temperature as well as indicating breadth of molecular weight distribution. The broader the molecular weight distribution, the more rapidly $\eta / \eta_{0}$ decreased. At higher shear rates/stresses, the data for the narrower distribution also falls off more rapidly. The author and his coworkers notably W. Minoshima and H. Yamane ${ }^{34), 35)}$ have instead prepared plots of $\eta / \eta_{0}$ vs. $\eta_{0} \dot{\gamma}$ and characterized distribution breadth with them. Such plots had been used earlier by Vinogradov and Malkin ${ }^{36), 37)}$ who noted theirt emperature independence but failed to find their mole cular weight distribution dependence. Yamane and White ${ }^{35)}$ have sought to quantify this dependence as shown.

There have been relatively few investigations of normal stresses in polymer melts. Pioneering early studies were made by $\mathrm{Han}^{38) \sim 40)}$, who noted that plots of $N_{1}$ versus $\sigma_{12}$ were independent of temperature. The author and his colleagues notably B.L. Lee, A. Kondo, K. Oda, W. Minoshima and H. Yamane $^{34), 35), 41 \sim 43)}$ have made extensive studies of normal stresses in polymer melts since about 1970. Plots of $N_{1}$ versus $\sigma_{12}$ were found to be molecular weight distribution-dependent with $N_{1}\left(\sigma_{12}\right)$ increasing with breadth of distribution. ${ }^{34), 35), 43)}$ 
The zero shear principal normal stress difference coefficient $\psi_{10}$ appears to vary with the 6 to 7 power of molecular weight. ${ }^{42)}$ The problem of the second normal stress difference $N_{2}$ in polymer melts has largely been ignored by rheologists. Those studies which have appeared ${ }^{44)}$ conclude $N_{2}$ to be zero or negative and significantly smaller than $N_{1}$. Similar conclusions were reached by B.L. Lee in our laboratories ${ }^{41}$.

Studies of uniaxial extension have become more extensive in recent years. Most early work emphasized low density poly. ethylene or polystyrene which could be easily drawn out as stable molten polymer filament. Many molten polymers however could not be drawn out in a stable manner. These drew the attention of the author and his coworkers includings Y. Ide, W. Minoshima and H. Yamane. ${ }^{34), 35), 45), 46)}$ It was found that broad molecular weight distribution linear polyolefins (polyethylenes, polypropylenes, polybutene-1s) readily develop necks and exhibit ductile failure. Narrowing of molecular weight distribution stabilizes the filaments and allows large elongations to break. This was first clearly shown by Minoshima et al. ${ }^{34)}$ but is most striking in Yamane and White's ${ }^{35}$ ) investigation of thermally decreased (viscracked) polypropylene and polybutene- 1 .

\section{Liquid Crystalline Polymers}

The discovery of liquid crystallinity in polymers is one of the more striking developments in recent years. The earliest material found to exhibit this behavior were concentrated solutions of polypeptides. ${ }^{47)}$ Attention, however, did not focus on this area until it was found that solutions of p-linked aromatic polyamides exhibited this behavior. ${ }^{48), 49)}$ These systems are unique in exhibiting structure under quiescent conditions which may be detected by polarized light microscopy. ${ }^{64) ~ 66)}$ Early studies of rheological properties generally emphasized that the shear viscosity of solutions went through a maximum at a critical concentration, where liquid crystallinity was first observed. ${ }^{48) \sim 50)}$ These results were confirmed in early studies in our laboratories by the author with J.F. Fellers, H. Aoki, Y. Onogi and J. Bheda and extended to solutions of cellulose derivatives. ${ }^{51) ~ 53)}$ Aoki et al. ${ }^{51)}$ found in working with p-linked aromatic polyamide liquid crystalline solutions, that these exhibited apparent yield values in shear flow. Similar characteristics have been found in solutions of cellulose derivatives. ${ }^{54)}$

It is also possible to produce bulk or thermotropic liquid crystalline polymers. Most efforts have emphasized polyesters ${ }^{54)} 60$ ) including the efforts of $\mathrm{H}$. Sugiyama and D.N. Lewis $\left.{ }^{60}\right)$ in our laboratories. Efforts of the author with J.F. Fellers, K. Shimamura, S. Suto and B.R. Liang were with cellulose derivatives. Shimamura, White and Fellers ${ }^{61)}$ showed that bulk hydroxypropyl cellulose (HPC) was liquid crystalline in character. Shortly thereafter Suto et al. ${ }^{62)}$ found that ethyl cellulose was similarly liquid crystalline. Liang et al. ${ }^{63)}$ found methyl cellulose to be a thermotropic liquid crystal. The behavior is apparently common among cellulose ethers but not cellulose esters. ${ }^{62), 63)}$ At higher temperatures there appears to be a phase transition from liquid crystalline to isotropic.

From about 1980, various investigators have reported rheological measurements on thermotropic liquid crystalline mate-

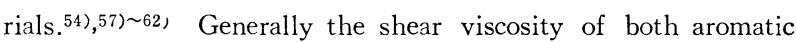
polyesters and cellulose ethers exhibits a yield value in the liquid crystalline regions (Fig. 1). The behavior of HPC is strikingly more complex. The viscosity (at moderate shear rates) decreases with increasing temperature in the liquid crystalline region but at about $200^{\circ} \mathrm{C}$ when the material becomes isotropic, the viscosity suddenly increases. At higher temperatures it decreases again ${ }^{62)}$ (see Fig. 1b).

\section{Particle Filled Polymer Systems}

There has been a long history of investigations of the rheological behavior of particle filled polymer systems ${ }^{20), 64) ~ 79)}$. It was observed by early investigators that the addition of particles

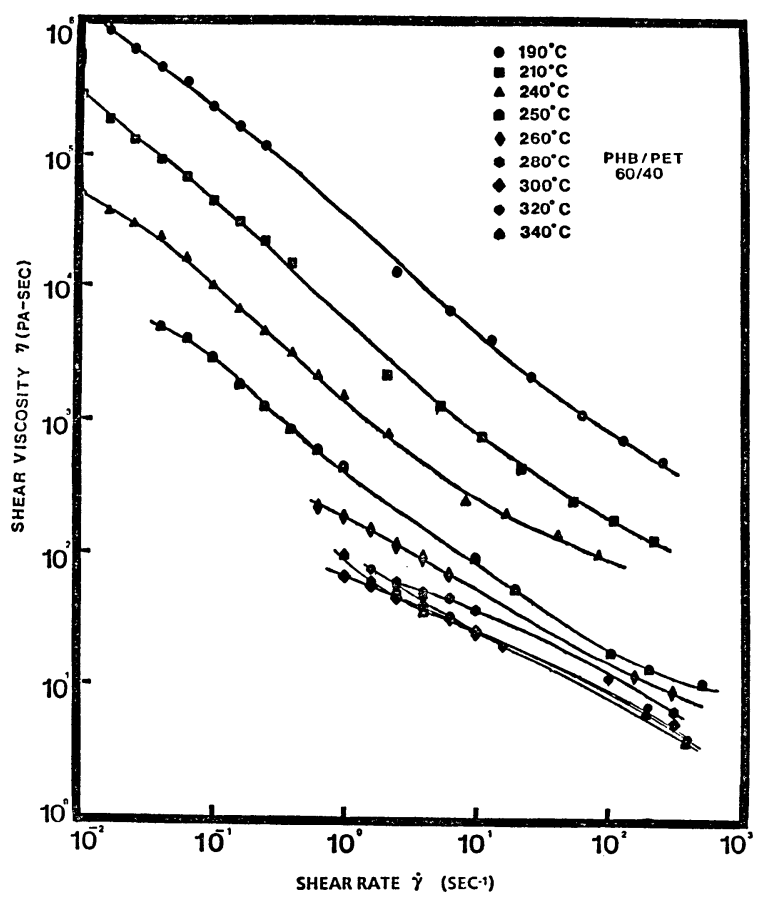

(a) poly(co-p-benzoate ethylene terephthate)

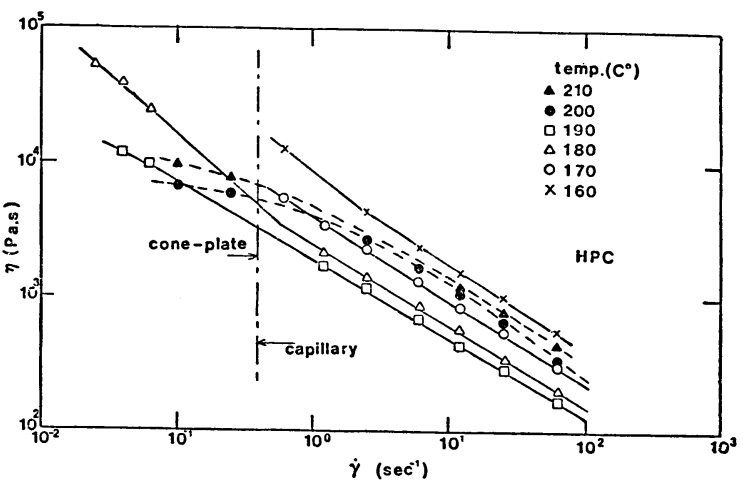

(b) hydoxypropyl cellulose

Fig. 1 Plot of shear viscosity versus shear rate for thermotropic liquid crystalline polymers. 
increased viscosity and that the level of increase depended upon particle type, being generally greater for smaller particles. ${ }^{67)}$ Polymer melts filled with large glass spheres exhibited low shear rate Newtonian viscosities ${ }^{68}$, but Russian investigators found that rubber filled with carbon black exhibited shear flow yield values. ${ }^{64)},{ }^{66}$ ) Talc compounds had also been found to exhibit yield values in shear flow. ${ }^{65)}$

From the mid 1970s, the author and his coworkers, notably N. Minagawa, V.M. Lobe, Y. Oyanagi, Y. Chan, L. Czarnecki, H. Tanaka, S. Toki, B.A. Knutsson, S. Montes and Y. Suetsugu, began a systematic investigation of the influence of particulates of varying types on the rheological properties of molten plastics and elastomers. ${ }^{67), 70) \sim 79)}$ These studies involved shear as well as elongational viscosity and shear flow normal stresses. Systems filled with glass and organic chopped fibers exhibited viscosity-shear rate behavior resembling pure unfilled polymer melts. ${ }^{71,74) \sim 76)}$ However, compounds filled with carbon black $\left.\left.\left.{ }^{72)}, 73\right), 77\right), 78\right)$, calcium carbonate $\left.{ }^{73)}, 79\right)$ and titanium dioxide $^{70), 73)}$ exhibited shear flow yield values. The magnitude of the yield value increased inversely with decreasing particle size as shown in work with Suetsugu ${ }^{79)}$ (Fig. 2). These yield values appear associated with small particle size and high surface area per unit volume.

Chopped fiber filled polymer melts exhibited striking rheological characteristics. This includes much higher principal normal stress differences at specific shear stresses than unfilled melts ${ }^{71)},{ }^{74)},{ }^{75)}$ and abnormally large elongational viscosities which decreased with increasing stretch rate. ${ }^{71}$ The magnitude of ${ }^{t}$ he normal stress $N_{1}$ was found to increase with fiber aspect ratio and rigidity (Fig. 3). The magnitude of $N_{1}$ decreases with extent of fiber damage during mastication. $N_{1}$ is larger for glass or aramid fiber filled compounds as contrasted to compounds with cellulose fibers ${ }^{74)}$.

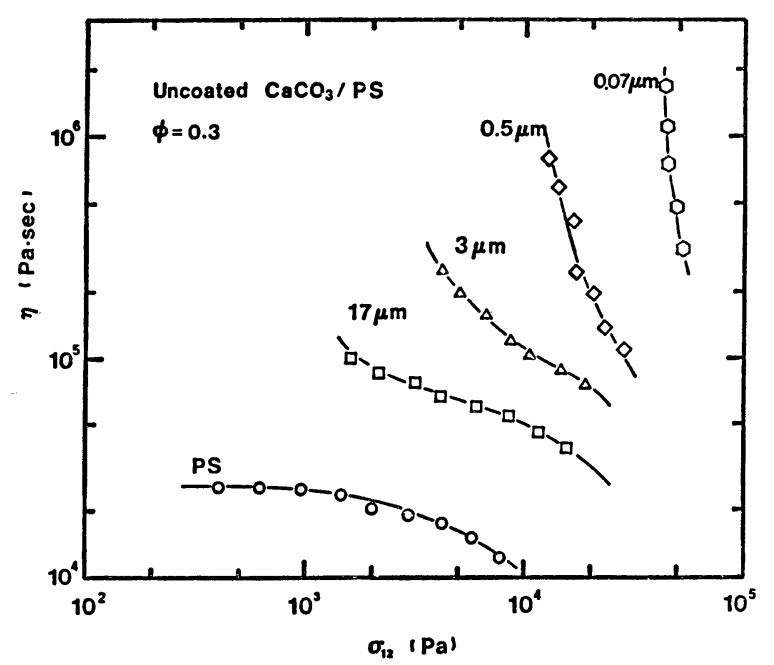

Fig. 2 Shear viscosity as a function of shear stress for a polystyrene melt filled with 30 volume percent calcium carbonate.
Small particle filled compounds with more than 15 volume percent loadings exhibited yield values in uniaxial extension as well as in shear flow. ${ }^{72), 73), 79)}$ Generally the yield values in extension were larger than these measured in shear with a ratio of 1.7. Normal stresses proved difficult to measure in particlefilled compounds, due to the failure of the stresses developed to compress the material between the cone and plate (or parallel plates) to relax ${ }^{79}$. The systems also exhibited strong thixotropic behavior, with excessively long times being required to forget past deformation history. This was not viscoelastic response as it was unaccompanied with the associated rheological effects that this would entail.

\section{CONSTITUTIVE EQUATIONS FOR RHEOLOGICALLY COMPLEX MATERIALS}

\section{Differential Viscoelastic Fluid Theories}

In the late 1940 s and early 1950 s Oldroyd ${ }^{80), 81)}$ established methods for formulation of 3-dimensional constitutive equations relating stress and deformation history in non-linear fluids.

During the early 1960s, the development of useful constitutive equations for polymer melts to simply analyze processing operations was of increasing major concern to the author. The author with A.B. Metzner proposed the form ${ }^{82)}$

$$
\begin{aligned}
& \boldsymbol{\sigma}=-p \boldsymbol{I}+\boldsymbol{P} \\
& \boldsymbol{P}=2 \eta \boldsymbol{d}-\tau \frac{\delta \boldsymbol{P}}{\delta t}
\end{aligned}
$$

where $\boldsymbol{\sigma}$ is the total stress tensor, $\boldsymbol{P}$, the extra stress tensor, $\boldsymbol{d}$, the deformation rate tensor and $\boldsymbol{I}$ the unit tensor. The viscosity and relaxation time $\tau$ are both considered to depend upon the invariants of the deformation rate (or the extra stress tensor) in a similar or identical manner. This predicted simple

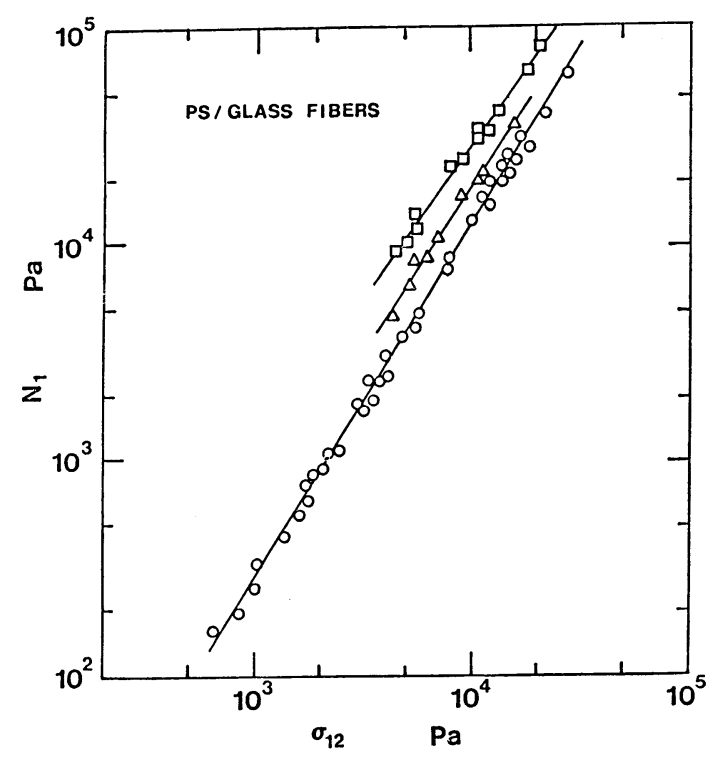

Fig 3. Principal normal stress difference of polystyrene melts filled with chopped fibers. 
useful forms for the stress field in shear flow,

$$
\begin{aligned}
& \sigma_{12}=\eta \dot{\gamma} \\
& N_{1}=2 \eta \tau \dot{\gamma}^{2}=\frac{2 \sigma_{12}^{2}}{G} \\
& N_{2}=0
\end{aligned}
$$

where $G$ is a presumably constant modulus term. If $\sigma_{12}$ (or $\eta$ ) has the general form of the viscosity-shear rate curve, the terms in $N_{1}$ and $N_{2}$ are in reasonable agreement with the experimentally determined characteristics mentioned above. In uniaxial extension, Eqs. (2) and (4), the stress response is

$$
\sigma_{11}=\chi \frac{\mathrm{d} v_{1}}{\mathrm{~d} x_{1}}=\frac{3 \tau G}{\left(1-2 \tau \frac{\mathrm{d} v_{1}}{\mathrm{~d} x_{1}}\right)\left(1+\tau \frac{\mathrm{d} v_{1}}{\mathrm{~d} x_{1}}\right)} \frac{\mathrm{d} v_{1}}{\mathrm{~d} x_{1}}
$$

At high extension rates $\mathrm{d} v_{1} / \mathrm{d} x_{1}$, the stress $\sigma_{11}$ and elongation viscosity $\chi$ both tend to infinity when

$$
\frac{\mathrm{d} v_{1}}{\mathrm{~d} x_{1}} \rightarrow \frac{1}{2 \tau}
$$

The constant elongational viscosity at low stretch rates followed by an unbounded rise at higher stretch rates has been described by various investigators for particular systems as described earlier.

The general formulation of the above constitutive equation requires making the relaxation time $\tau$ and the viscosity $\eta$ a function of deformation rate. These are usually taken to have the same form. The dependence is represented through

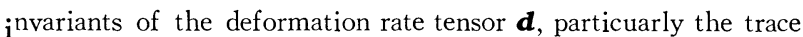
tr (sum of diagonal components) of the products of $\boldsymbol{d}$ with itself. Two formulation used have been, a power law form $1^{\text {argely applied by Denn }}{ }^{81)}$.

$$
\tau=K I I_{\mathrm{d}}^{(n-1) / 2}
$$

where

$$
I I_{\mathrm{d}}=2 \operatorname{tr} \boldsymbol{d}^{2}
$$

and one by Y. Ide and the author ${ }^{46), 84)}$ (compare Bogue ${ }^{85)}$ )

$$
\tau=\frac{\tau_{0}}{1+a \tau_{0}} \overline{I I_{\mathrm{d}} 1 / 2}
$$

which includes representation of the low deformation rate linear viscoelastic and constant zero shear rate behavior.

\section{Integral Viscoelastic Fluid Models}

The differential equation models of Oldroyd and others are one of the approaches that has been taken to representing viscoelastic behavior. They indeed all seriously suffer from only roughly representing small strain linear properties. Lodge ${ }^{86)}$ developed the approach of generalizing Boltzmann's integral theory of linear viscoelasticity. Lodge simply stated his integral forms with various rough phenomenological or molecular justifications. However the work of Green and Rivlin ${ }^{87)}$ and Coleman and Noll ${ }^{88)}$ using the theory of functionals made clear that this was not generally the case and that the stress should be expressed as infinite expansion of single and multiple integrals of deformation history. The formulation of Lodge ${ }^{84)}$ represents the first term in the expansion.
However by the early 1960s it seemed clear that the Lodge formulation proved a useful starting point for empirical nonlinear theories of viscoelasticity which could better quantiatively represent extensive data from a wide range of experiments than the differential models discussed above. The first to take this approach at least with a major commitment were Bernstein, Kearsley and Zapas ${ }^{89), 90)}$, who carried out an extensive experimental program in conjuction with this. They argued that the stress tensor should have the form

$$
\boldsymbol{P}=\int_{0}^{\infty}\left[m_{1}(z) \mathbf{c}^{-1}-m_{2}(z) \mathbf{c}\right] d z
$$

where $m_{1}(z)$ and $m_{2}(z)$ are functions of invariants of $\boldsymbol{c}^{-1}$ and $\boldsymbol{c}$.

In the 1960s and 1970s various additional investigators ${ }^{89)}$ (91) introduced and tested constitutive equations of the form of Eq. (13). The author with D.C. Bogue in this period developed a constitutive equation of this form with ${ }^{92}$ )

$$
\begin{aligned}
& m_{1}(z)=\left(1+\frac{\varepsilon}{2}\right) \sum \frac{G_{1}}{\tau_{\text {ieff }}} \exp \left(-t / \tau_{\text {ieff }}\right) \\
& m_{2}(z)=-\frac{\varepsilon}{2} \sum \frac{G_{1}}{\tau_{\text {ieff }}} \exp \left(-t / \tau_{\text {ieff }}\right)
\end{aligned}
$$

where $\tau_{\text {ieff }}$ is an effective relaxation time defined by

$$
\tau_{\text {ieff }}=\frac{\tau_{\mathrm{i} 0}}{1+a \tau_{\mathrm{i} 0} I I_{\mathrm{d}}{ }^{1 / 2}}
$$

where $\overline{I I_{\mathrm{d}}{ }^{1 / 2}}$ is a time averaged square root of the second invariant of the rate of deformation tensor. This was compared shortly thereafter by I.J. Chen ${ }^{95)}$ in his PhD Dissertation with Bogue to experimental studies of shear flow in polyethylene melts. Subsequently Chen who remained at the University of Tennessee as a post-doctoral fellow together with a larger team ${ }^{9)}$ contrasted the response to uniaxial extension data on low density polyethylene as well. The agreement was generally good. Subsequent comparisons of theory and experiment for polystyrene were also good.97)

\section{More Complex Materials : Plastic-Viscoelastic Fluids}

Many important polymer systems are much more complex than the homogeneous polymer melts representable by viscoelastic fluid theory. This includes polyvinyl chloride which is processed below its crystalline melting point and rubber modified thermoplastics such as ABS resins and filled thermoplastics. There has been little effort at developing constitutive equations from such materials. The problem of representing the rheological behavior of polymer melts filled with high volume fractions of small particles became of concern to the author in the 1970s. Substantial progress was first made with the $\mathrm{PhD}$ researches of V.M. Lobe on the rheological properties of carbon black filled polystyrene. As these materials exhibit shear and uniaxial extension yield values, Hohenemser and Prager ${ }^{98)}$ and Oldroyd's ${ }^{80}$ 3-dimensional theory of Bingham plastics seemed a logical place to begin. The formulation proposed by the author has the form ${ }^{99}$

$$
\boldsymbol{\sigma}=\frac{1}{3}(\operatorname{tr} \boldsymbol{\sigma}) \boldsymbol{I}+\boldsymbol{T}
$$




$$
\mathbf{T}=\frac{Y(t)}{\sqrt{\frac{1}{2} \operatorname{tr} \mathbf{T}^{2}}} \mathbf{T}+\boldsymbol{H}
$$

where $\boldsymbol{T}$ is the deviatoric stress tensor, $\boldsymbol{H}$ is a deviatoric memory functional i.e.

$$
\operatorname{tr} \mathbf{T}=\operatorname{tr} \boldsymbol{H}=0
$$

and $Y(t)$ represents a history dependent yield stress. The formulation described above is awkward as it is not explicit in stress. It was shown by the author that $\mathbf{T}$ could be written explicitly as

$$
\boldsymbol{T}=\frac{Y(t)}{\sqrt{-\frac{1}{2} \operatorname{tr} \boldsymbol{H}^{2}}} \boldsymbol{H}+\boldsymbol{H}
$$

$Y(t)$ has been represented by Y. Suetsugu ${ }^{100)}$ with the form

$$
Y(t)=Y_{\mathrm{i}}-\left[\int_{0}^{\infty} \alpha I I_{\mathrm{d}}^{1 / 2} \exp \left(-\alpha I I_{\mathrm{d}}^{1 / 2} z\right) \mathrm{d} z\right]\left(Y_{\mathrm{i}}-Y_{\mathrm{f}}\right)
$$

where $Y_{\mathrm{i}}=Y_{\mathrm{f}}+\beta I I_{\mathrm{d}}{ }^{1 / 2}$

Here $\alpha$ and $\beta$ are constants.

The author together with V.M. Lobe, H. Tanaka and Y. Suetsugu(100) 102) have introduced specific forms for the $\boldsymbol{H}$ functional and contrasted them with experiment. The form used is

$$
\boldsymbol{H}=\int_{0}^{\infty} \mu(z)\left[\mathbf{c}^{-1}-\frac{1}{3}\left(\operatorname{tr} \mathbf{c}^{-1}\right) \boldsymbol{I}\right] \mathrm{d} z
$$

where $\mu(z)$ is a memory function. The earlier studies ${ }^{101), 102)}$ which involved constant $Y$ parameters contrasted steady state results with experiment. The more recent studies with Suetsugu have used Eq. (21) or $Y(t)$ and contrasted transient as well as steady state experimental results with theory. The comparison is promising.

The author has moved towards developing both general and asymptotic formulations of Eq. (19). This has included specific asymptotes for long duration shear flows ${ }^{103)}$ and slow flows ${ }^{104)}$. For slow flows one has order fluids analogous to those which arise in viscoelastic fluid mechanics. The zeroth order fluid is the same as the theory of perfectly plastic solids of von Mises ${ }^{105)}$. The first order fluid is Oldroyd's form of the Bingham plastic. ${ }^{80)}$

Carbon black filled rubber compounds generally exhibit slippage and boundary condition need to be critically examined. Mooney ${ }^{18)}$ was deeply concerned about this. More recently Tokita and the author ${ }^{77)}$ have investigated this problem.

\section{DIMENSIONAL ANALYSIS}

\section{General}

One of the traditional key aspects of engineering analysis of flow and heat transport in fluid systems in engineering systems is the use of dimensional analysis. The procedures date to Osborne Reynolds ${ }^{106}$ ) investigation of the laminar-turbulent transition in tpipeline flow of Newtonian fluids. During the 1940s and 50s, various engineers sought to apply dimensionless analysis to flow of non-Newtonian fluids. The efforts of Metzner ${ }^{107)}$ and others largely concentrated on modified Reynolds numbers for pipeline flows and equivalent dimensionless groups for convective heat transfer. However the broader context of dimensionless groups which would characterize the specific nonNewtonian character was not broached.

\section{Isothermal Viscoelastic Fluids}

The concept of dimensionless groups which would characterize the viscoelastic responses in non-Newtonian fluids dates to Weissenberg ${ }^{107)}$ in 1947 , who saw intuitively that the recoverable shear strains played the key note. Weissenberg's views were represented by Philippoff ${ }^{106)}$ in succeeding years. In the mid 1960s, the author and his colleagues ${ }^{109) \sim 112)}$ sought to develop the concepts of Weissenberg using the theory of nonlinear visccelastic fluids. It was shown using procedures similar to those applied by Reynolds that the behavior of viscoelastic fluids was dominated by the dimensionless group $\tau_{\mathrm{ch}} U / L$ where $\tau_{\mathrm{ch}}$ is characteristic time and $L$ a characteristic of length. For a Maxwell model it can be seen that

$$
\tau_{\mathrm{ch}} \frac{U}{L}=\frac{\eta}{G} \frac{U}{L}=\frac{\sigma}{G}=S \text { (recoil) }
$$

The new dimensionless group is essentially the same as Weissenberg's recoverable strain. For this reason it was first called by the author the Weissenberg Number.

The Weissenberg number takes on a special significance for situations in which the deformation rate is in the direction of flow. We may write

$$
\tau_{\mathrm{ch}} \frac{U}{L_{11}^{-}}=\frac{\tau_{\mathrm{ch}}}{L_{11} / U}=\frac{\tau}{t_{\mathrm{res}}}
$$

where $L_{11}$ is a characteristic length in the direction of flow and $t_{\text {res }}$ is the residence time. The Weissenberg number in these circumstances is thus the ratio of the material time to the residence time. The proposal of this ratio as being a key one in rheology is due to Reiner ${ }^{113)}$ proceeding from basically different intuitive arguments. He refers to Eq. (23) as the Deborah number.

The dimensionless group $\tau_{\mathrm{ch}} U / L$ represents the basic group determining both isothermal scale-up characteristics and the onset of hydrodynamic instabilities. Characteristic velocities should be increased in proportion to characteristic dimensions in scaling. The usual occurence of instabilities in polymer processing operations at characteristic shear stresses independent of apparatus dimensions suggests that this $\tau_{\mathrm{ch}} U / L$ dimensionless group is indeed appropriate.

However there are many phenomena in polymer processing which cannot be correlated with the Weissenberg number and indeed constitutive equations contain many additional parameters beyond a relaxation time and modulus/viscosity. In the authors earliest paper on the subject ${ }^{135)}$, this point is directly discussed and "viscoelastic ratio' numbers are described. More recently W. Minoshima and the author ${ }^{114}$ ) have considered this problem in light of both various constitutive equations and the observed hydrodynamic response of real materials. It was concluded that the key dimensionless group involved the deformation rate dependence of the relaxation time. 
For a relaxation time given by Eq. (11a), this parameter is the power law exponent ' $n$ '. If Eq. (12) is used for the relaxation time, the ' $a$ ' paramter is obtained.

White and Minoshima ${ }^{140)}$ name this dimensionless group after Misaszo Yamamoto who considered the deformation rate dependence of relaxation spectra for non-linear viscoelastic constitutive equations. ${ }^{115)}$

\section{Isothermal Plastic Fluids}

Dimensional analysis for Bingham plastic fluids was initiated by Oldroyd ${ }^{23)}$ who showed that the deviations from Newtonian flow characteristics may be represented by a ratio of plastic yielding to viscous shearing forces. Specifically

$\frac{\text { Plastic yielding forces }}{\text { Viscous shearing forces }}=\frac{Y}{\eta_{\mathrm{B}} U / L}=\frac{Y L}{\eta_{\mathrm{B}} U}$

The dimensionless group indicates scaling with respect to $U / L$. This was called the Bingham number by Prager ${ }^{116)}$.

The author with D.C. Huang ${ }^{117}$ ) has given attention to the problem of dimensional analysis for plastic viscoelastic fluids which are differentially viscoelastic above their yield values. They note that two dimensionless groups arise, the Bingham number of Eq. (24) and the Weissenberg number $\tau_{\mathrm{ch}} U / L$ described above.

\section{Non-Isothermal Flow}

Polymer melts and elastomers have high viscosities. They are processed at elevated temperatures. They generate large quantities of heat as they flow in dies, in extruders, etc. One cannot consider polymer processing operations in terms of rheological analyses and balances of forces. The energy equation and the interaction of heat generation, heat conduction and convection need to be considered. These give rise to new dimensionless groups involving ratios of energy fluxes. These are given by ${ }^{118)}$

$$
\begin{aligned}
& \text { Heat generation }=\frac{\eta U^{2}}{k \theta} \\
& \text { Heat condhction }=\frac{\eta}{k \theta} \\
& \text { Heat } \text { convection } \frac{L U \rho c}{k}
\end{aligned}
$$

These are generally referred to as the Brinkman and Peclet numbers. ${ }^{118)}$

\section{REPRESENTATION AND CHARACTERIZATION OF STRUCTURE IN ORIENTED POLYMERS}

\section{General}

The industrial rheologist must be concerned not only with the behavior of materials during flow but with the characteristics of these materials after the completion of flow and subsequent vitrification. This includes the details of solidification, of whether there is vitrification or crystallization, the levels of molecular orientation developed and the formation of residual quench stressess.

\section{Uniaxial Orientation}

Perhaps the most important structural feature of polymers influenced by flow is molecular orientation. It has long been recognized that quantities such as birefringence, dichroic behavior and anisotropic diffraction of $\mathrm{x}$-rays represented molecular orientation. However there was no quantitative manner of expressing this. Such a procedure was initiated by P.H. Hermans ${ }^{11), 13)}$ who represented orientation in terms of anisotropy of the polarizability tensor, $\alpha_{\mathrm{ij}}$. He restricted himself to the uniaxial orientation in fibers. Hermans showed that

$$
\frac{\alpha_{11}-\alpha_{22}}{\Delta \alpha_{0}}=f_{\mathrm{H}}=\frac{\overline{3 \cos ^{2} \phi_{1 \mathrm{c}}}-1}{2}
$$

Here $\alpha_{\mathrm{ij}}$ are components of the polarizability tensor, $\Delta \alpha_{0}$, the intrinsic (maximum) difference in polarizabilities and $\phi_{1 \mathrm{c}}$ is the angle between individual polymer chains and the fiber axis. Hermans et al. ${ }^{13)}$ showed how $f_{\mathrm{H}}$ could be obtained from $\mathrm{x}$-ray diffraction measurements for crystalline materials or regions. For homogeneous materials, Hermans noted that the quantity $f_{\mathrm{H}}$, now known as the Hermans orientation factor, is the ratio of the measured birefringence to the intrinsic birefringence. In a later paper ${ }^{119)}$ they noted that in semicrystalline fibers, the amorphous and crystalline regions would be expected to have different orientations and x-ray and birefringence could be used to obtain $f_{\mathrm{H}}$ for both regions.

A broader perspective was introduced by Stein ${ }^{120}$ ) who noted that $\mathrm{x}$-ray diffraction could be used to determine the orientation of three crystallographic axes as well as the chain axis, which usually coincides with the c-crystallographic axis. He defines

$$
f_{\mathrm{j}}=\frac{\overline{3 \cos ^{2} \phi_{1 \mathrm{j}}}-1}{2}
$$

where the angle $\phi_{1 \mathrm{j}}$ is between the $j$ crystallographic axis and the fiber axis.

The Hermans-Stein arguments described above have two limitations. First they are limited to uniaxial fiber orientatation. Secondly they represented averaged orientations. The first problem we will consider in the next section. The problem of polymer chain orientation distributions and crystallographic axis orientation distributions have been discussed by Muller ${ }^{12}$ and by Roe and Krigbaum ${ }^{121}$. They show that the Hermans-Stein orientation factor represents the first term in a Legendre polynomial expansion for the orientation distribution function.

\section{Biaxial Orientation}

The representation of more complex states of orientation in polymer systems such as biaxial orientation in films was initiated by Stein ${ }^{122)}$ in 1958 who represented orientation in terms of Euler's angles defined relative to axes embedded in the polymer film. These efforts were extended in a series of papers by Nomura, Kawai, Kimura and Kagiyama. ${ }^{122) \sim 125)}$ They proposed a second set of orientation factors based on Euler's angles. This allows not only definition of biaxial orientation factors but expansion of the orientation distribution function in terms of an expansion in associated Legendre polynomials. A different view of representing orientation has been developed 


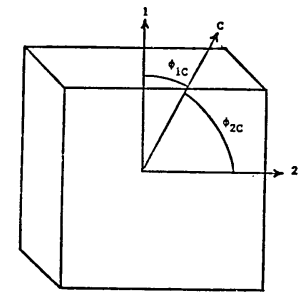

(a)

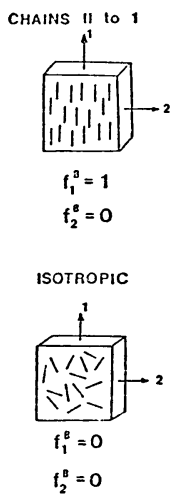

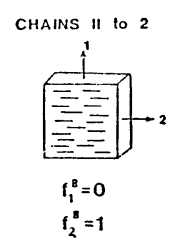

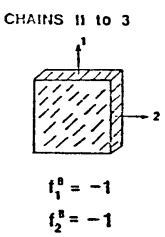

planar equal biaxial
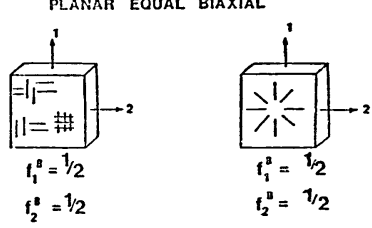

(b)

Fig. 4 Representations of orientation uniaxial orientation (upper line) and biaxial orientation (lower line)

in papers by Desper and Stein ${ }^{126)}$ and by White and Spruiell. ${ }^{127)}$ They formulated an analysis of the anisotropy of the polarizability tensors in terms of the angles $\phi_{\mathrm{c} 1}$ and $\phi_{\mathrm{c} 2}$ between the polymer chain axis and the machine ' 1 ' and transverse ' 2 ' directions of the film or similar section. The orientation representations developed in this manner are symmetric with the ' 1 ' and ' 2 ' directions which make them a convenient representation of orientation (see Fig. 4a)

The specific definitions developed in our laboratories ${ }^{127)}$ was:

$$
\begin{aligned}
& f_{1} \mathrm{~B}=2 \overline{\cos ^{2} \phi_{\mathrm{c} 1}}+\overline{\cos ^{2} \phi_{\mathrm{c} 2}}-1 \\
& f_{2} \mathrm{~B}=2 \overline{\cos ^{2} \phi_{\mathrm{c} 2}}+\overline{\cos ^{2} \phi_{\mathrm{c} 1}}-1
\end{aligned}
$$

For uniaxial orientation in the machine direction:

$$
\overline{\cos ^{2} \phi_{\mathrm{c} 2}}=\overline{\cos ^{2} \phi_{\mathrm{c} 3}}=\frac{1}{2}\left[1-\overline{\cos ^{2} \phi_{\mathrm{c} 1}}\right]
$$

This reduces $f_{1}{ }^{\mathrm{B}}$ to P.H. Hermans' Eq. (27) and $f_{2}$ B to zero. For equal biaxial orientation $f_{1} \mathrm{~B}$ and $f_{2} \mathrm{~B}$ are equal. If the polymer chains are normal to the surface of the film,

$$
\overline{\cos ^{2} \phi_{3 \mathrm{c}}}=1 \quad \overline{\cos ^{2} \phi_{\mathrm{c} 1}}=\overline{\cos ^{2} \phi_{\mathrm{c} 2}}=0
$$

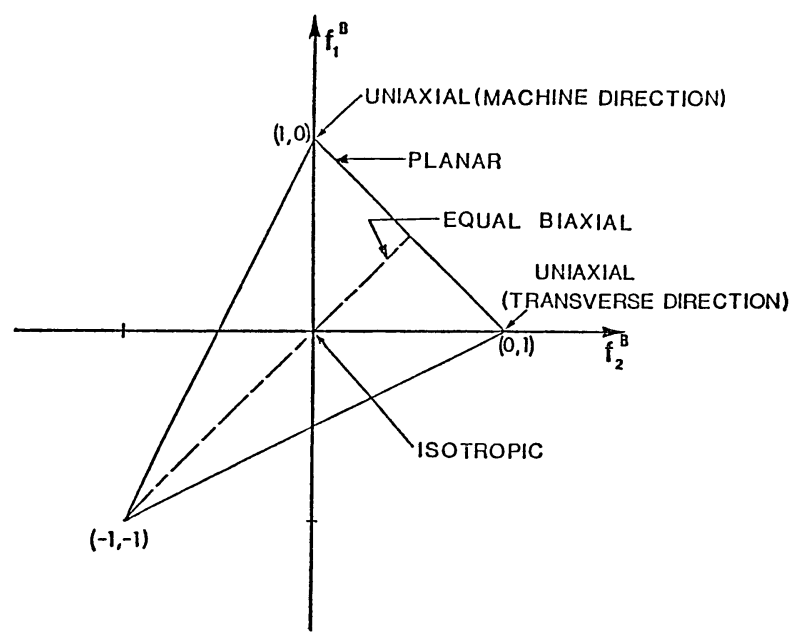

Fig. 5 Orietation triangle. and

$$
f_{1} \mathrm{~B}=f_{2} \mathrm{~B}=-1
$$

The orientation factors are both negative.

These various states of orientation may be conveniently expressed in terms of an isosceles triangle in a plane with coordinates $f_{1} \mathrm{~B}$ and $f_{2} \mathrm{~B}$ as shown in Fig. 5 . The base of the triangle represents the planar orientation and the vertex the state of normal orientation described in Eqs. (32). The altitude of the triangle is the state of equal biaxial orientation where $f_{1} \mathrm{~B}$ and $f_{2} \mathrm{~B}$ are equal. (Fig. $4 \mathrm{~b}$ )

Orientation Development during Flow of Flexible Chain Polymer Melts

It has long been realized that molecular orientation develops during flow of polymer solutions and melts. The discovery of this effect indeed as mentioned earlier dates to Clerk Maxwell. ${ }^{3}$ A quantitative view of the relationship of orientation to stress and deformation was developed by Kuhn and Grun ${ }^{8)}$ and Treloar ${ }^{128)}$ for vulcanized rubber, i.e. network of flexible chains. This may be expressed

$$
\boldsymbol{n}=\frac{1}{3}(\operatorname{tr} \boldsymbol{n}) \boldsymbol{I}+C \mathbf{T}
$$

where $C$ is the stress optical constant. Stein et al. ${ }^{129)}$ and Saunders ${ }^{130}$ ) showed that birefringence was proportional to stress during stress relaxation in unvulcanized samples. Lodge ${ }^{84)}$ presented arguments based on extending Kuhn and Grun's model for birefringence to systems with temporary network junctions or entanglements. A subsequent series of papers by Philippoff and his coworkers ${ }^{131)}$ verified this for polymer solutions and Janeschitz-Kriegl, Wales and their colleagues ${ }^{132) \sim 134)}$ and Han and Drexler ${ }^{135)}$ for molten polyethylene, polypropylene and polystyrene. Matsumoto and Bogue ${ }^{136)}$ have verified Eq. (33) for polystyrene in elongational flow for isothermal and nonisothermal conditions.

As noted by K. Oda and the author ${ }^{169)}$, the rheo-optical law 
of Eq. (33) may be restated in terms of orientation factors for homogeneous amorphous polymers. For the orientation factors of Eq. (29), this relationship is

$$
f_{1}^{\mathrm{B}}=\frac{C}{\Delta^{\mathrm{0}}}\left(\sigma_{1}-\sigma_{3}\right) \quad f_{2}^{\mathrm{B}}=\frac{C}{\Delta^{\mathrm{0}}}\left(\sigma_{2}-\sigma_{3}\right)
$$

The ratio $C / \Delta^{\circ}$ deserves discussion. The stress optical constant $C$ and intrinsic birefringence $\Delta^{\circ}$ have both been analyzed in terms of the molecular characteristics of matter. The quantities $C^{8), 128)}$ and $4^{0137)}$ are both primarily dependent upon and indeed proportional to the difference in polarizabilities along and perpendicular to the chain. The ratio should be expected to be a roughly temperature-independent constant. ${ }^{138)}$

\section{Flow Induced Orientation in Vitrified Samples of}

\section{Flexible Polymer Chains}

Consider the vitrification of a polymer melt under an applied stress field as would occur in the processing of a glass forming polymer. In the molten state, the state of orientation and birefringence would be related to the stress field through Eqs. (38) and (39). The question arises as to the nature of birefringence in fabricated parts. This generally comes from two sources: (i) Birefringence developed during melt flow and (ii) birefringence associated with thermal quench stresses. ${ }^{139)}$ The relative magnitudes of birefringence from these two sources depend upon the two stress-optical constants, $C$, and the magnitude of the stresses. The stress-optical constant associated with thermal quench stresses is that below the glass transition temperature, $T_{\mathrm{g}}$, while that associated with flow orientation is the value in the molten state. The relative values of $C$ above and below $T_{\mathrm{g}}$ depend upon the backbone structure of the polymer. $C$ is roughly the same for all amorphous polymers below $T_{\mathrm{g}}$. At temperatures higher than $T_{\mathrm{g}}$ it depends upon $\Delta \alpha_{0}$, the polarizability difference along and perpendicular to the polymer chain. Polymers such as polystyrene, polycarbonate and polyethylene terephthalate possess phenyl groups in the backbone or along the chain. This leads to large $\Delta \alpha_{0}$ and flow

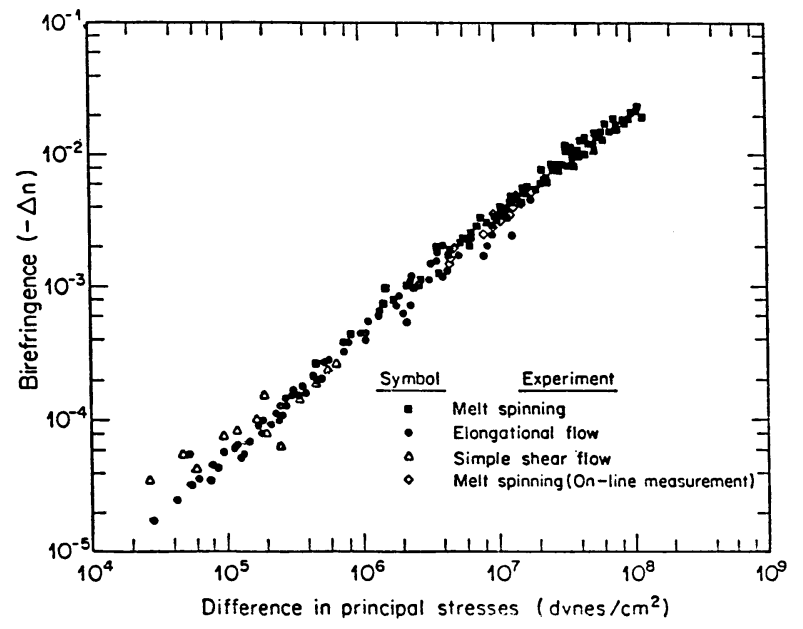

Fig. 6 Frozen-in-birefringence of polystyrene as a function of stress at vitrification. birefringence dominating thermal quench stress birefringence.

The author and K. Oda ${ }^{138)}$ have investigated the mechanisms of 'frozen-in' birefringence in polystyrene stretched filaments, sheared slabs and melt spun filaments. They showed that the birefringence was proportional to the difference in principal stress (Fig. 6) and that the proportionality constant was the same as the melt state stress-optical constant. The result was later confirmed by Choi et al. ${ }^{140)}$ for tubular film extrusion of polystyrene. The total set of kinematics studied included uniaxial extension, biaxial extension and shear.

\section{Polymer Liquid Crystals}

The rheo-optical characteristics of liquid crystalline polymers exhibit considerable differences from those of flexible polymer chains. First liquid crystalline polymers exhibit complex morphologies in the state of rest as revealed by the polarized light microscope. The influence of deformation on the morphology of liquid crystalline polymer solutions has been investigated extensively by S. Onogi and Asada ${ }^{141)}$ through the years and by Y. Onogi ${ }^{142}$ ) in our own laboratories. These studies have largaly emphasized the disruption of the rest state morphology and its mechanisms. The researches of Y. Onogi ${ }^{142)}$ showed that very high levels of orientation developed during flow compared to the magnitudes of the stresses involved. $\mathrm{He}$ also found that birefringence decayed away only very slowly following cessation of flow.
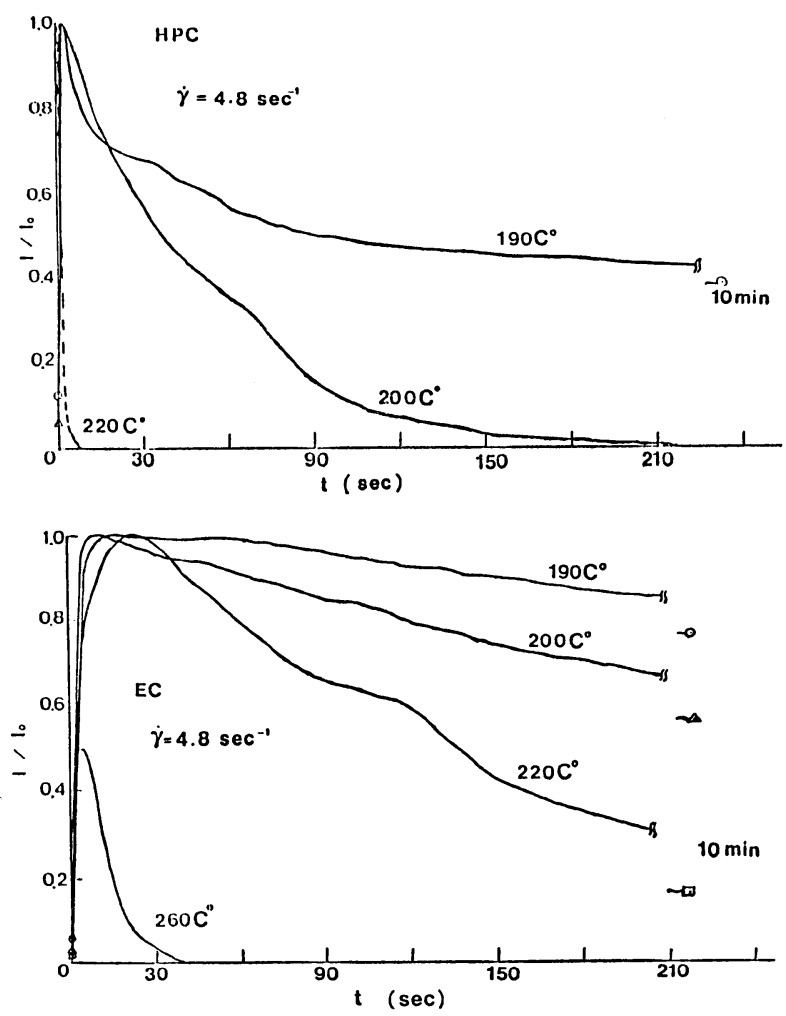

Fig. 7 Decay of birefringence following cessation of flow in thermotropic polymer liquid crystals; hydroxypropyl cellulose and ethyl cellulose. 
The influence of deformation on the phase morphology of thermotropic liquid crystalline polymers has been investigated using a shear device with glass slides on polarized light microscope hot stage by K. Shimamura ${ }^{61)}$ and S. Suto ${ }^{62)}$ working with the author and J.F. Fellers. The birefringence developed during flow decays away only very slowly following the cessation of deformation (Fig. 7).

The results of Y. Onogi, Shimamura and Suto cited above have striking implications for processing. High levels of orientation are developed, which do not have time to decay away before normal solidification.

\section{EXTRUSION}

\section{General}

No processing operation is more important than extrusion. Extrusion is one of the oldest of processing operations with patents on ram extrusion through dies dating to the 1840 s and the screw extrusion process to the $1870 \mathrm{~s}$. The area of the single screw extruder design has undergone enormous development in the past generation as described in recent papers by Hermann ${ }^{143)}$ and Johnson. ${ }^{144)}$ Screw extruders are used in the rubber industry which contain (i) pins in the barrel which interfere with the movement of the rubber along the screw and (ii) screws which interpenetrate the barrel and the transported material must move back and forth. We have seen the development and exploitation of twin screw extruders ${ }^{145)}$ which can be either co-rotating or counter-rotating. The former are widely used for compounding. More unique is the development by Tadmor and his coworkers of the corotating disk or Diskpack processor ${ }^{146)}$ in which the screw is replaced by a series of parallel disks mounted on a shaft.

There is a literature based on investigations of flow of polymer melts in both screw geometries and in dies. Studies of flow in single screw extruders have undergone enormous expansion. Prior to 1965 there had been an increasing sophistication of analyses of melt flow in the metering region of the screw near the die. It was however only with the studies of the melting region of the screw by Tadmor and his coworkers ${ }^{147), 148)}$ that fully integrated models and studies of screw extrusion were possible. This has now given rise to an enormous literature.

The efforts of the above paragraph should be classified more as engineering innovation and design as opposed to rheology. Studies of flow in dies have always been more part of the general thrust of rheology and we shall consider these in succeeding paragraphs.

\section{Flow Through Dies-Polymer Melts}

The problem of flow of polymer melts into the entrance of dies gives rise to complex flow patterns, in particular in many polymer melts to large vortices (Fig. 8). Such vortices were first described in 1957-60 for low density polyethylene. ${ }^{149), 151)}$ It was found that no vortices existed for high density polyethylenes. ${ }^{151)}$ There was until the 1970s little interest in * other polymer melt systems though Clegg ${ }^{152)}$ noted a lack of vortices in polyvinyl chloride and though Giesekus ${ }^{153}$ had described vortex development in polyisobutylene and polyacrylamide in the late 1960s. This problem was investigated from 1969 by the author with T.F. Ballenger and later A. Kondo. ${ }^{41), 154)}$ It was found that polystyrene exhibited vortices as well as low density polyethylene but polypropylene behaved like high density polyethylene and exhibited no vortices. Furthermore the size of the vortices increased with extrusion rate. The large vortices were associated with large die end pressure losses, i.e. the pressure loss in addition to that due to friction along die walls.

White and Kondo ${ }^{41)}$ associated the vortices with the magnitude of the deformation rate softening behavior (Yamamoto number) (compare White and Minoshima ${ }^{114)}$ ). The level of deformation rate softening strongly influences the elongational flow behavior in the die entrance region. Small values of this parameter lead to large vortices and large values to the absence of vortices.

Crochet and his coworkers ${ }^{155)}$ and others have been seeking to simulate this behavior using finite element numerical solutions. They find the results very sensitive to the detailed form of the constitutive equations used.

Another and probably more important problem in die entrance flows is the flow distribution problem where we seek to design dies which will assure uniform flows through a wide sheet or annulus. These types of problems have been analyzed by Pearson ${ }^{156)}$, and later investigators. ${ }^{157)}$

Fully developed flow in a die is an area which has received abundant attention in the literature. Bingham's 1922 "Fluidity and Plasticity" contains Buckinghams analysis of the velocity profile and pressure drop-flow rate relationship for a Bingham plastic. There have been many solutions of this problem since that time. Most have emphasized the power law fluid. Parallel plate, circular tube and annular solutions are summarized in

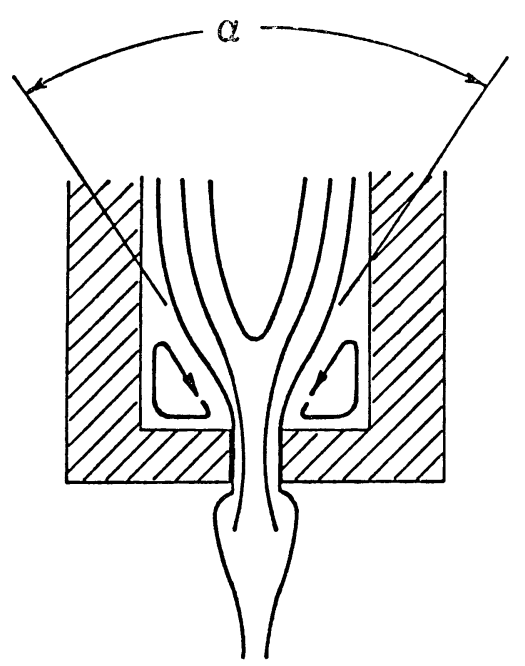

Fig. 8 Vortices in a die entrance region. 
tabular form in the text of Tadmor and Gogos ${ }^{157)}$. Rectangular cross-sections have been treated by a number of authors beginning with Schechter ${ }^{158)}$ and Wheeler and Wissler ${ }^{159)}$ (see also Rothemeyer ${ }^{160)}$ and White and Huang ${ }^{161)}$ ).

Much attention has been given to the suggestion of Ericksen ${ }^{162)}$ and Green, Langlois and Rivlin ${ }^{163)}$ that non-Newtonian fluids with second normal shear differences should exhibit vortices perpendicular to the direction of flow. These vortices have been observed by several investigators ${ }^{202), 203)}$ for polymer solutions. They would seem of little importance for the dies with short lengths used with polymer melts.

One major area of interest in flow through dies has been the problem of pressure losses. The total pressure loss is the sum of entrance, fully developed flow and exit pressure losses i.e.

$$
p_{\mathrm{T}}=\Delta p_{\mathrm{ent}}+\Delta p_{\mathrm{fd}}+\Delta p_{\mathrm{exit}}
$$

where $\Delta p_{\text {ent }}$ is the entrance pressure loss, $\Delta p_{\mathrm{fd}}$ is the fully developed flow and $\Delta p_{\text {exit }}$ that at the exit. Bagley ${ }^{166)}$ first called attention to the importance of the total excess pressure effect. Han et al. ${ }^{39), 167)}$ clearly separated them into entrance and exit effects. The calculation of these phenomena from first principles is still a matter of great difficulty and some controversy. The entrance effect clearly depends on entrance geometry and elongational flow characteristics.

The characteristics of emerging extrudates has received enormous attention. The emerging melts swell to values greater than that of the dimensions of the die for simple dies. Theories of varying levels of sophistication have been proposed through the years beginning with Spencer and Dillon ${ }^{168)}$ to represent the swell. The simplest model still retaining some level of sophistication is that proposed by Tanner ${ }^{169)}$ based on a single integral constitutive equation with a single relaxation time. This led to swell depending on Weissenberg number of $N_{1} / \sigma_{12}$ to roughly the $1 / 3$ power at the die wall. This was subsequently generalized to other geometries by D.C. Huang and the author ${ }^{161), 170), 171)}$ including long slits trapezoids and rectangular cross-section dies as well as short $L / D$ dies. The long slit result is

$$
\left(\frac{h}{H}\right)=0.2+\left[1+\frac{1}{12}\left(\frac{N_{1}}{\sigma_{12}}\right)_{\mathrm{w}}^{2}\right]^{1 / 4}
$$

Swell from a slit is larger than a capillary. Huang and White generalize this to allow $N_{1}$ to empirically depend on $\sigma_{12}$ to an arbitrary power which gives some improvement between theory and experiment.

The above analyses were extended by White and Huang ${ }^{170)}$ to trapezoid and rectangles by applying Eq. (36) and its generalization as a function of lateral position along the width of dies. The results are compared to experiment in Fig. 9.

The problem of very short $(L / D \rightarrow 0)$ capillary and slit dies was treated by Huang and White arguing that the flow into the entrance is long duration elongational flow. Reasonable

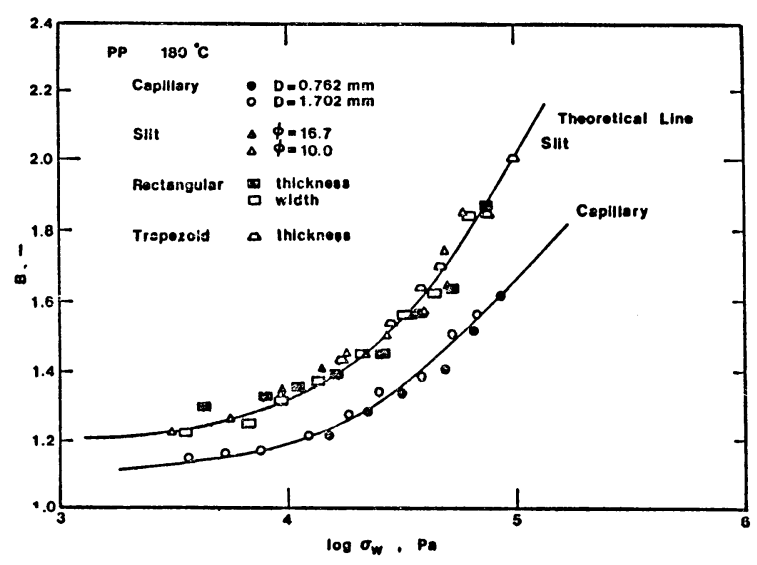

(a)

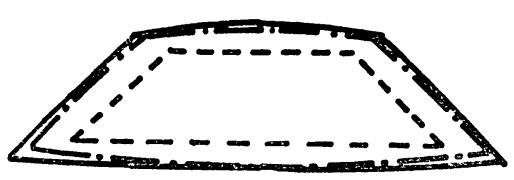

-- - die shape

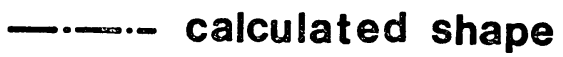

- experimental shape

(b)

Fig. 9 Extrudate swell from long capillary, slit, trapezoidal and rectangular dies versus theory (a) and predicted and experimental profiles for a trapezoidal die (b).

agreement is found with experiment.

The above analyses have the weakness in that they consider fully developed flow extending to the exit of the die. This leads to a discontinuity. The flow must instead rearrange near the die exit. It is no longer possible to obtain analytical solutions. Tanner ${ }^{172}$ ) and his coworkers were the first to point this problem out and to present numerical simulations. More recent studies for various viscoelastic models have been reported by Reddy and Tanner ${ }^{173)}$ and Crochet and Keunings. ${ }^{174)}$

Another area of great interest is the distortion of extrudates as they emerge. This problem was first studied by Spencer and Dillon ${ }^{175)}$ in the 1940s and by Tordella ${ }^{176) \sim 178)}$ a decade later. It occurs as a critical die wall shear stress of about $10^{5}$ Pascal and two instability mechanisms would appear to occur. From flow visualization studies instabilities in many melts seem to be initiated by a spiralling flow into the entry. ${ }^{149), 154)}$ For other melts the instability would seem to be initiated by slip within the die. ${ }^{178)}$ The phenomena would appear to be a hydrodynamic instability phenomena associated with a critical Weissenberg number. This problem has been treated theoreti- 
cally by Denn and his coworkers. ${ }^{179)}$

\section{Flow Through Dies-Thermotropic Liquid Crystalline}

\section{Polymers}

There has been little study of entrance flows for liquid crystalline polymer (though see Shimamura et al. ${ }^{61)}$ ). The extrudate characteristics of liquid crystalline polymers emerging for long dies have received attention and are striking. Various investigators have noted for both aromatic polyesters ${ }^{57), 58), 60)}$ and for cellulose ethers ${ }^{62)}$ that there is essentially no extrudate swell. The extrudates furthermore exhibit significant levels of uniaxial orientation as determined by $\mathrm{x}$-ray diffraction and birefringence. ${ }^{60), 61)}$ Hermans orientation factors of 0.6 have been measured. Generally the extrudates are also fibrillated. ${ }^{60) \sim 63)}$ These phenomena can be qualitatively explained. The lack of extrudate swell is associated with the existence of a yield value (compare White and Huang ${ }^{117)}$ ) and the lack of orientation recovery. There would seem a sound rationale for the residual orientation based on the very slow relaxation of orientation recovery. There would seem a sound rationale for the residual orientation based on the very slow relaxation of orientation (birefringence) following flow described by Shimamura et al. ${ }^{61)}$ and Suto et al. ${ }^{62)}$ The fibrillation of the extrudates is probably an anisotropic response due to thermal quench stresses associated with weak lateral forces.

\section{Flow Through Dies-Filled Polymers}

There has been little interest in the problem of flow patterns in filled polymers in the entrance region of dies. Recently $\mathrm{Ma}$ et al., in our laboratories ${ }^{180)}$, has studied the flow of small particle filled polyethylene and synthetic rubber. The addition of more than five volume percent filler eliminated the vortices and led to streamline entrance flows which converge into the die entry.

Filled polymers emerging from dies show substantially reduced extrudate swell. ${ }^{66), 67), 70), 71), 72), 76)}$ In compounds filled with small particles, the behavior is associated with yield values (see White and Huang $\left.{ }^{117}\right)$ ). In compounds filled with fibers this is assoicated with the fibers retaining their orientation. ${ }^{76}$ ) Based on a suggestion by T. Kitao ${ }^{181)}$, Menendez and White ${ }^{182)}$ have studied the orientation of aramid fibers in polymethyl methacrylate extrudates using wide angle $\mathrm{x}$-ray diffraction and obtain equivalent Hermans orientation factors. Values of order 0.45 are obtained within the die and 0.3 in the extrudates.

\section{FIBER FORMATION}

\section{General}

The formation of fibers and textile products is the basis of a major industry though the former which is applied to polyester, nylon and polypropylene is dominant. It is also possible to produce non-woven fabrics directly from melt filaments using air jets and conveyor belts or drums. Melt spinning and one spunbonding technology are contrasted in Fig. 10. New spinning technologies have been developed in which pitch is melt spun into fibers and subsequently pyrolized to form carbon fibers and rogano-metalic polymers melt spun and pyrolized to form ceramics.

Research on fiber spinning prosess technologies has emphasized increasing process rates, modelling of the spinning operation and study of spinning instabilities as well as structure development during melt spinning.

\section{Melt Spinning Dynamics and Spunbonding}

Modelling of the melt spinning process dates to the work of Ziabicki and Kedzierska ${ }^{183), 184)}$ who reported force balances
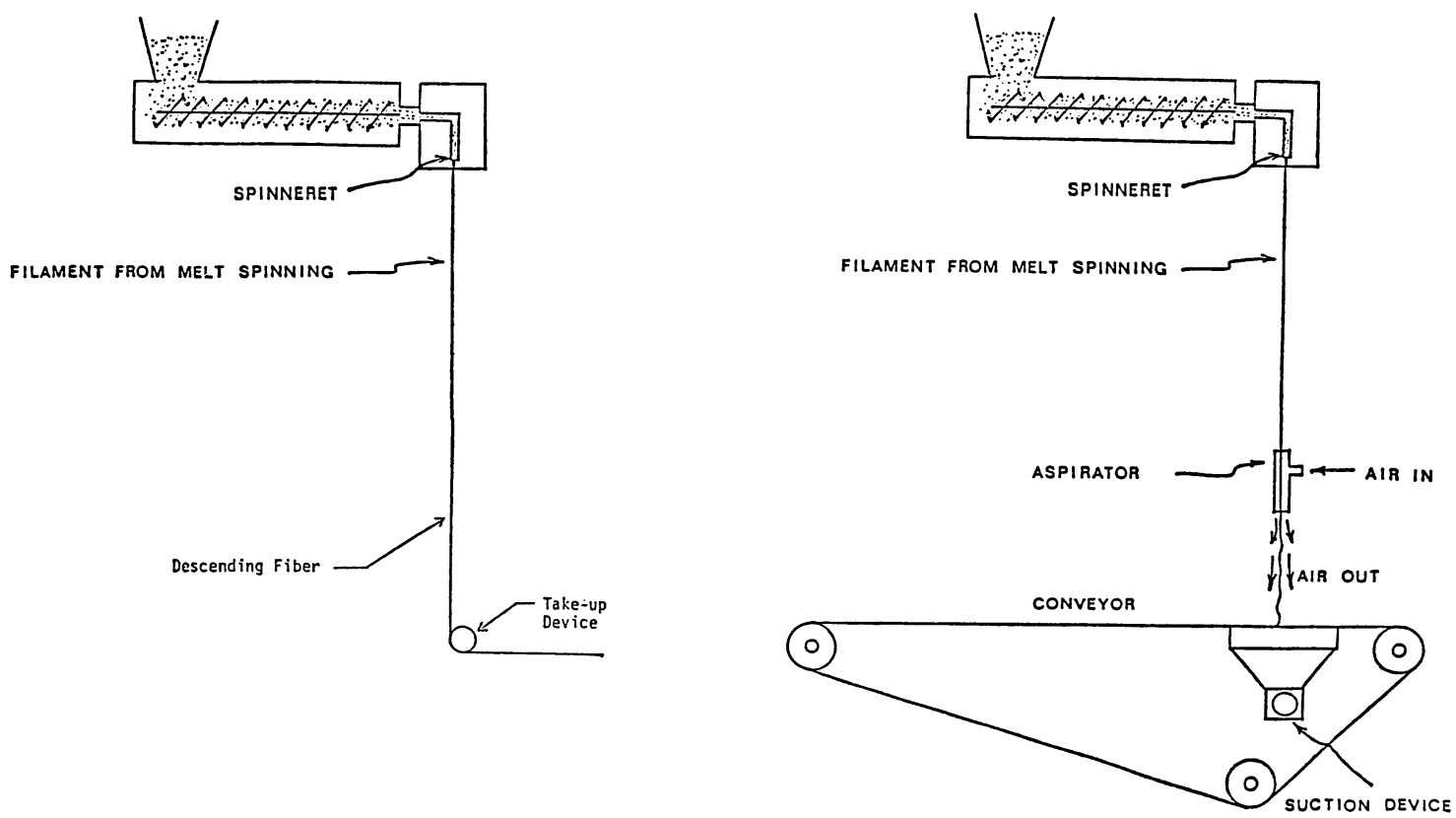

Fig. 10 Melt spinning and spunbonding. 
and analyses for the spinline. They expressed the forces on the spinline as

$$
F_{\mathrm{x}}=F_{\mathrm{L}}+F_{\mathrm{drag}}-F_{\mathrm{grav}_{\mathrm{r}}}-F_{\mathrm{mom}}
$$

where $F_{\mathrm{x}}$ is the tension at position $x, F_{\mathrm{L}}$ at the bobbin, $F_{\text {drag }}$ is due to air drag, $F_{\text {grav }}$ due to gravity and $F_{\text {mom }}$ due to changes in momentum flux. This must be coupled with an energy balance ${ }^{185)}$

$$
c G \frac{\mathrm{d} T}{\mathrm{~d} x}=-\pi d h\left(T-T_{0}\right)
$$

where $G$ is the mass flow rate, $c$ heat capacity, $d$ fiber diameter, $h$ local heat transition coefficient and $T$ temperature. The heat transfer coefficient has been determined by Kase and Matsuo. ${ }^{185)}$ The relative magnitudes of the forces have been investigated over a wide range of process conditions. At low drawdown ratios $v_{\mathrm{L}} / v_{0}, F$ is equal to $F_{\mathrm{grav}_{\mathrm{r}}}$ an asymptote analyzed by Trouton ${ }^{186)}$ for isothermal Newtonian fluids. As $v_{\mathrm{L}} / v_{0}$ becomes larger, take-up tension becomes increasingly important and $F_{\mathrm{X}}$ comes to roughly equal $F_{\mathrm{L}}$. This asymptote has been most widely studied and used as the base of models of the melt spinning process by Kase and Matsuo ${ }^{185)}$, Denn and coworkers ${ }^{187), 188)}$ and others ${ }^{189)}$ for various rheological models and cooling conditions. At higher $v_{\mathrm{L}} / v_{0}$ drag forces and momentum fluxes become increasingly important. High speed melt spinning has been most thoroughly studied by Shimizu and his colleagues. ${ }^{190)}$

In spunbonding the fibers are drawn down by an aspirator (Fig. 10). The dynamics of spunbonding have been analyzed and experimentally investigated by C.H. Chen and the author. ${ }^{191)}$ They are basically equivalent to Eq. (37) with the air drag within the aspiration replacing the tension of the take-up roll. It was found that the tension exerted by the aspiration was related to the velocity of the high speed ai rthrought the same relations governing air drag in melt spinning.

\section{Instability Phenomena}

Various spinline instabilities have been described through the years, the most important of which is draw resonance, a periodic instability which has been found to occur in both

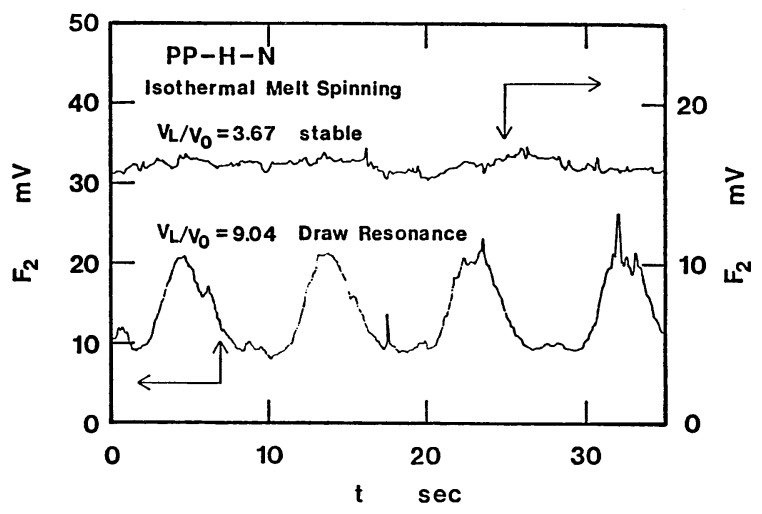

Fig. 11 Onset of draw resonance in melt spinning of polypropylene. melt spinning of fibers and cast film. ${ }^{192) ~ 197)}$ This is illustrated in Fig. 11.

The mechanism of this instability was derived in basic studies by Kase, Matsuo and Yoshimoto ${ }^{193)}$ and Pearson and Matovich ${ }^{198)}$ which analyzed this problem for isothermal Newtonian fluids. This work was subsequently generalized for non-Newtonian viscous ${ }^{199)}$ and viscoelastic materials ${ }^{188)}$ as well as for non-isothermal effects. ${ }^{200}$ Generally factors leading to increasing differential elongational viscosities along the threadline were found to be stabilizing.

Studies in the author's laboratories by Y. Ide, W. Minoshima and H. Yamane ${ }^{189), 196), 197)}$ have shown that the onset of draw resonance correlates with ductile necking instabilities in molten filaments drawn in an isothermal bath. Draw resonance is a continuous process analog of this phenomenon. ${ }^{189)}$ In terms of dimension analysis, the critical $V_{\mathrm{L}} / V_{0}$ is dominated by Yamamoto number (see White and Minosbima ${ }^{114}$ ).

The onset of draw resonance correlates with breadth of molecular weight distribution and the occurrence of long chain branching. Narrowing the distribution of polyolefins has been found to be stabilizing. ${ }^{195) ~ 197)}$ Even more stabilizing is the introduction of long chain branching. ${ }^{189}$ ) These differences correlate both with differential elongational viscosity and neck development/failure in uniaxial extension.

\section{Structure Development}

Melt spun fibers are oriented. The influence of process conditions on the structure of melt spun fibers received relatively little attention until the 1970s. Pioneering studies of structure development in melt spinning were reported in papers by Katayama, Amano and Nakamura ${ }^{201)}$ and Hamana, Matsui and Kato. ${ }^{202)}$

In the decade of the 1970s a research program was initiated by J.E. Spruiell, the author and their coworkers. Oda et al. ${ }^{138)}$ showed that in melt spinning of vitrifying polystyrene fibers, the birefringence developed during flow was 'frozen-in'. Thus Eqs. (34) is valid. Omotoso et al. ${ }^{203)}$ found this to be valid for high impact polystyrene as well. This result was also obtained for polyethylene terephthalate by Hamana et al. ${ }^{202}$ )

Various investigations from our laboratories studied the melt spinning of crystallizing polymers including polyethylene ${ }^{204)}$ 206), polypropylene ${ }^{207)}{ }^{208)}$, nylon-6 ${ }^{209)}$, nylon-66210) and most recently polyvinylidene fluoride. ${ }^{211}$ Many of these investigations have involved on-line studies of structuring. Many researchers, including our group, have used on-line birefringence to characterize crystallization in the spinline. The use of on-line x-ray diffraction was pioneered by Katayama et al. ${ }^{201)}$ and by Dees and Spruiel1205), who determined crystallization kinetics. Later studies involving the author applied this to polypropylene ${ }^{208)}$ and nylon-6. ${ }^{209)}$ Under the conditions studied, nylon-6 was found by Bankar209) to not crystallize on the spinline but rather on the bobbin. Apparently the polymer vitrifies, but 


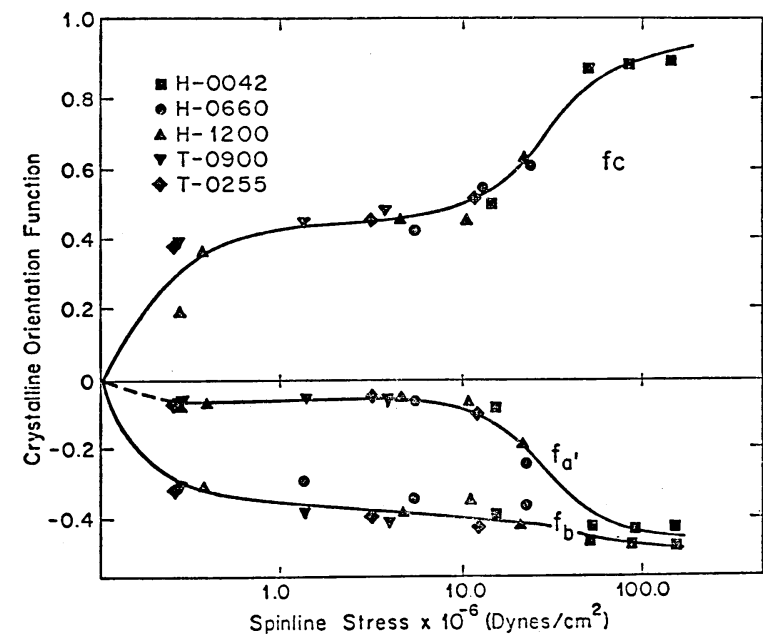

Fig. 12 Orientation factors as a function of spinline stress for polypropylene at varying molecular weight.

absorption of moisture lowers $T_{\mathrm{g}}$ below room temperature allowing it to crystallize.

The relationship of orientation in crystalline fibers to spinline processing conditions has been investigated by various researchers. Kitao and his coworkers ${ }^{212), 213)}$ represented the orientation of melt spun fibers in terms of Hermans-Stein crystalline orientation factors. It was found for polyethylene and polypropylene fibers, that at low draw down ratios, the $\boldsymbol{b}$ axis becomes perpendicular to the fiber axis. The $\mathbf{c}$-axis orientation factor $f_{\mathrm{c}}$ increases with drawdown ratio. Dees and Spruiell ${ }^{261)}$ found that the orientation factors $f_{\mathrm{j}}$ correlate with the spinline stress. This was extended in succeeding studies by H.M. Henson and H. P. Nadella with Spruiell and the author on polypropylene. ${ }^{207), 208)}$ Using different melt spinning temperatures and polymers of varying molecular weight, it was shown that the orientation was still a unique function of spinline stress (see Fig. 12). C.H. Chen ${ }^{191)}$ showed that this relationship was valid as well for fibers drawn down by an aspirator. More recently $Y$. Wang, M. Cakmak and the author ${ }^{211}$ have found this also to be true for polyvinylidene fluoride.

\section{Thermotropic Liguid Crystalline Polymers}

The melt spinning of thermotropic liquid crystalline hydroxypropyl cellulose was investigated by Shimamura et al. ${ }^{61)}$ and aromatic polyesters by Sugiyama et al. ${ }^{60)}$ As noted in an earlier section, extrudates, i.e. no drawdown and $v_{\mathrm{L}} / v_{0}$ of unity had significant levels of uniaxial orientation. Hermans orientation factors were of order 0.6. With increasing drawdown or spinline stress, $f_{\mathrm{H}}$ showed little tendency to increase further.

\section{FILM}

\section{General}

Film has been an area of major technological expansion during the past generation. New materials have been produced and films have been produced for many new applications. These range from very strong biaxially oriented high density polyethy- lene to polyvinylidene fluoride and poly ( $\mathrm{p}$-phenylene terephthalamide). Various procedures are used to produce film including (i) the tubular process (ii) slit extrusion (casting) followed up by a tentering frame and (iii) solution processes. These procedures were originally developed for low density polyethylene, polystyrene and regenerated cellulose respectively but are now widely applied. Research in different laboratories has included both studies of the dynamics of these processes and development of structural order/orientation in them as well as now process technologies.

\section{Tubular Film : Dynamics and Stability}

While the tubular film process (Fig. 13) dates to the 1940s, it was only about 1970 that the basic kinematics and dynamics received careful attention at the hands of Pearson and Petrie. ${ }^{214}$ ) These authors derived expressions for the kinematics. The kinematics may be roughly represented in terms of a drawdown ratio $v_{\mathrm{L}} / v_{0}$, blow up ratio $B=R_{\mathrm{L}} / R_{0}$ and a frostline height $z_{\mathrm{L}}$.

The dynamics of the process are specified by

$$
\begin{aligned}
& F_{\mathrm{L}}=2 \pi R H \sigma_{11} \cos \theta+\pi \Delta p\left(R_{\mathrm{L}}{ }^{2}-R^{2}\right) \\
& \Delta p=\frac{H \sigma_{11}}{R_{1}}+\frac{H \sigma_{22}}{R_{2}}
\end{aligned}
$$

These must be combined with an energy balance. There have been few basic experimental studies of the detailed kinematics of the tubular film process. T. Kanai and the author ${ }^{215)}$ have presented detailed measurements of kinematics, stresses and temperature in a laboratory tubular film machine study of low density, high density and linear low density polyethylenes. An expression was developed for the local heat transfer coefficient.

Beginning with Pearson and Petrie ${ }^{214}$ various authors have sought to model the tubular film process. Their study was for isothermal Newtonian fluids. Later investigations have included non-isothermal and non-Newtonian fluid characteristics. ${ }^{216) \sim 218)}$

Tubular film processes are notoriously unstable. These

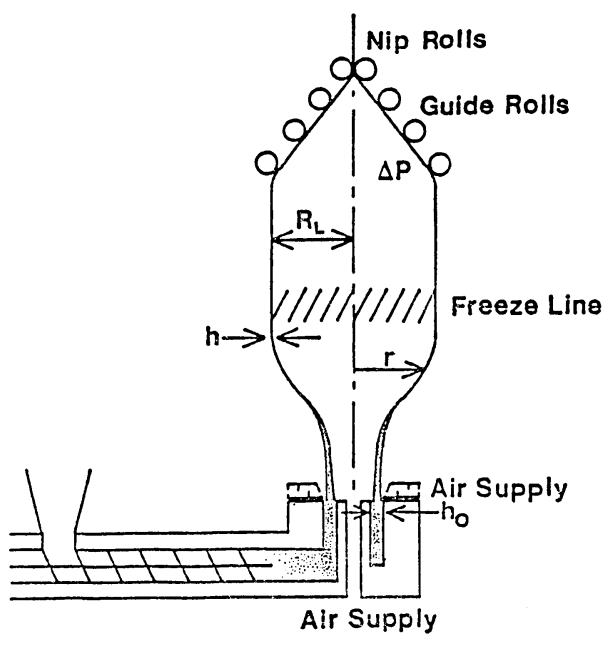

Fig. 13 Tubular Film Process. 
instabilities were first discussed in the literature by Han and $\operatorname{Park}^{219)}$. They have since been extensively considered by $\mathrm{T}$. Kanai, W. Minoshima and the author. ${ }^{215), 220)}$ They have been mapped out in a 3-dimensional space of drawdown ratio $v_{\mathrm{L}} / v_{0}$, blowup ratio $R_{\mathrm{L}} / R_{0}$ and frostline height $z_{\mathrm{L}}$. Uniaxial drawdown is stable, but small inflation pressures produce instabilities over a range of $B$. Generally low density polyethylenes and broad molecular weight distribution high density polyethylenes and narrower molecular weight distribution high density polyethylenes are highly unstable.

\section{Tubular Film : Structure Development}

Studies of structure development in tubular film extrusion date back a quarter century to the work of Lindenmeyer and Lustig $^{221)}$ who presented pole figures for polyethylene tubular film. There have been more recent studies of the structure of film ${ }^{222), 223)}$, but it is only with the work of K.J. Choi, J.E. Spruiell and the author ${ }^{140), 224)}$ that this was methodically related to process conditions. Beginning with polystyrene film, they showed that Eq. (34) combined with Eqs. (39) and (40) could be used to predict orientation in the films. In a later study, the same authors ${ }^{224}$ found that the crystalline biaxial orientation factors $f_{\mathrm{j} 1} \mathrm{~B}, f_{\mathrm{j} 2}{ }^{\mathrm{B}}$ of polyethylene film were also determined by the stress fields and this dependence was the same as observed by Dees and Spruiell ${ }^{205)}$ for melt spun polyethylene fibers (Fig. 14). The orientation was much higher for the polyethylene film at the same stress level and more biaxial in character. Similar behavior was found by Shimomura et al. ${ }^{225}$ ) for polypropylene film.

Another important aspect of films is their haze. Huck and Clegg ${ }^{226)}$ related haze to internal scattering and surface roughness. More recently Stehling et al. ${ }^{227)}$ and Ashizawa, Spruiell and the author ${ }^{228}$ ) have shown that the surface roughness is dominant. The scattering of light by the roughness becomes greater as it increases in amplitude towards the wavelength of light. These authors also relate haze to process variables.

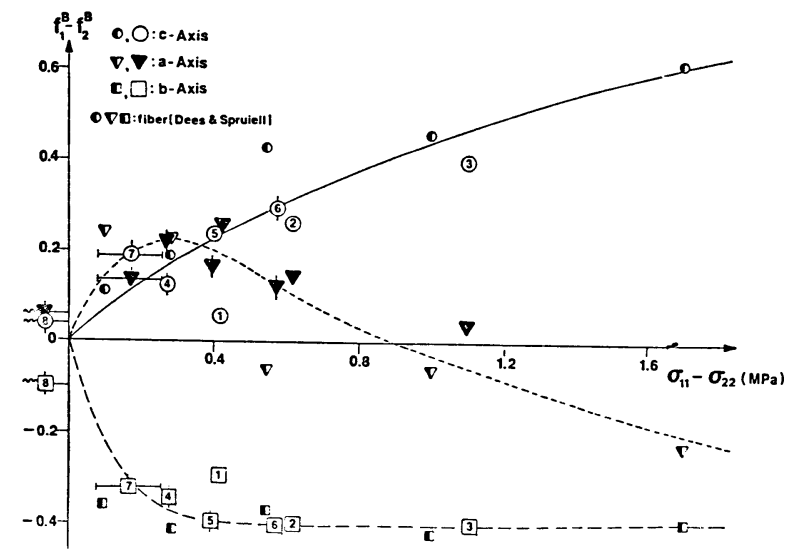

Fig. 14 Orientation factors for PE film vs. takeup stress.

\section{Biaxially Stretched Film}

The study of the characteristics of biaxially stretched film have a long history. Of greatest interest in biaxially stretched film is the tentering frame process where biaxial stretching of polyethylene terephthalate (PET) cast film takes place at temperatures above its glass transition temperature. This is followed by an annealing step which acts to further and perfect crystallization. There are no basic studies of the dynamics, heat transfer and structure development involved in these processes. This is a worthy area of future study.

Studies in our laboratories were pioneered by K. Matsumoto $^{229)}$, M.A. Omotoso and M. Cakmak. ${ }^{230), 231)}$ M. Cakmak, J. Spruiell and the author have investigated structure development in biaxial stretching and subsequent annealing of PET film. ${ }^{230213)}$ Orientation of polymer chains and phenyl groups were investigated using wide angle $\mathrm{x}$-ray diffraction and optical measurements. Biaxial orientation factors were computed representing chain directions and phenyl groups. The values of $f_{1 \mathrm{a}} \mathrm{B}$ and $f_{2 \mathrm{a}} \mathrm{B}$ for the chain approach to $+0.5, f_{1 \mathrm{a}} \mathrm{B}$ and $f_{2 \mathrm{a}} \mathrm{B}$ representing normals to the phenyl group are very negetive (see Fig. 15). These indicated the chain axes are equal biaxially distributed in the plane of the flow and phenyl groups are parallel to the surface of the film.

\section{Poly (p.Phenylene Terephthalamide) Films From Liquid Crystalline Solutions}

In the late 1970s, J.F. Fellers and the author undertook the task of developing films from poly (p-phenylene terephthalamide), the material of DuPont's Kevlar ${ }^{\circledR}$ fiber. Generally redissolved Kevlar ${ }^{\circledR}$ fiber in sulfuric acid was used as a starting material. In the earliest stages we worked with $\mathrm{H}$. Aoki on slit dies and annular dies with air inflation. ${ }^{232)}$ These produced uniaxial films which were brittle in the trantverse direction. In later studies with J.E. Flood ${ }^{233), 234)}$ an oil coated mandrel

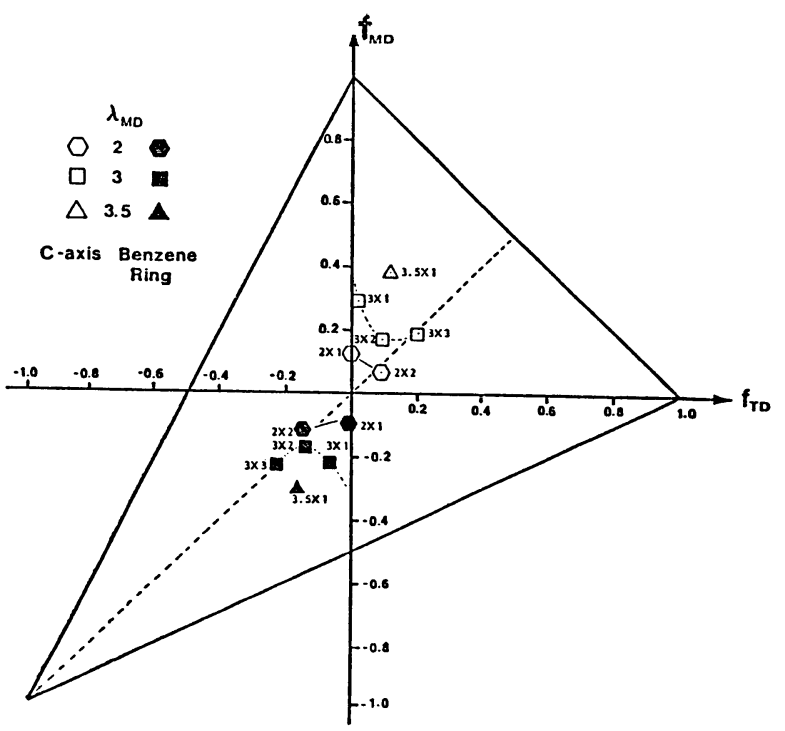

Fig. 15 Orientation triangle for PET films. 


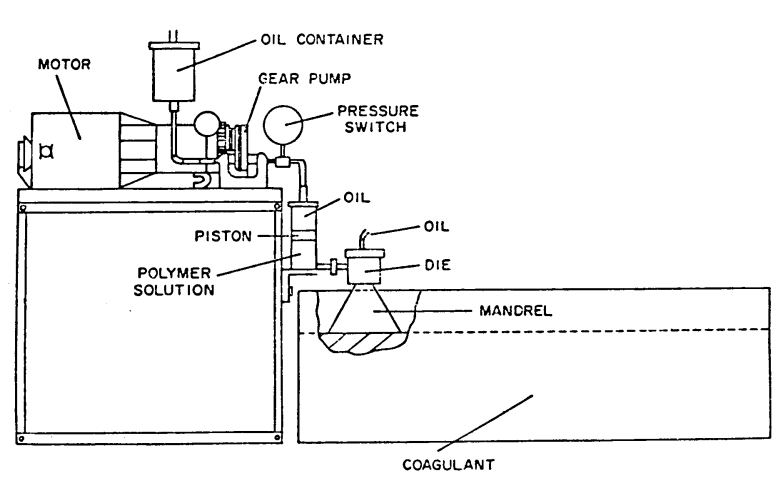

Fig. 16 Mandrel film process for solutions of poly (pphenylene terephthalamide) in $\mathrm{H}_{2} \mathrm{SO}_{4}$.

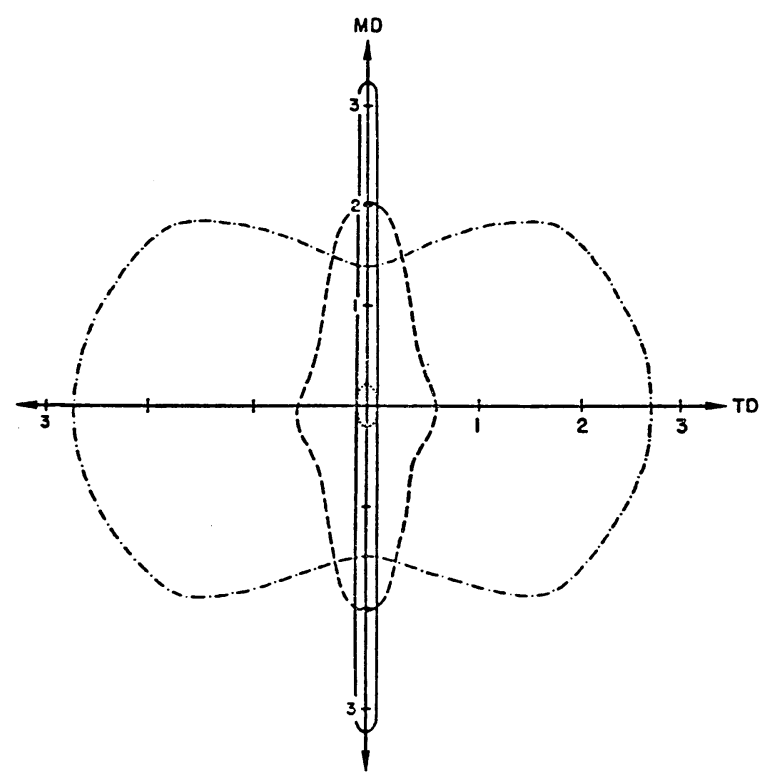

Fig. 17 Polar diagram of tensile strengths of PPD-7 films. Dotted line, extruded only; solid line, uniaxial drawdown; dash-dotted line, mandrel ; dashed line, mandrel with drawdown.

was placed below an annular die and a solution flowed out over the cone with biaxial kinematics. This process is shown in Fig. 16. Wide angle $x$-ray diffraction measurements showed that the polymer chains are biaxially oriented almost in the plane of the film. Values of $f_{1 \mathrm{c}}{ }^{\mathrm{B}}$ and $f_{2 \mathrm{c}}{ }^{\mathrm{B}}$ of 0.4 have been obtained. The WAXS results also indicate that the phenyl groups tend to lie in the plane of the film. The tensile strength of the film also becomes equal in all directions of the plane (Fig. 17). The basic problem appears to be redirection of the uniaxial orientation developed in flow through the die so nicely noted by Shimamura and others for thermotropic liquid crystals. The flow kinematics induced by the mandrel accomplish this.

\section{MOLDING OPERATIONS}

\section{General}

Molding operations include injection molding where melt is injected by pressure into a mold and blow molding where a viscous molten annular cylinder is inflated into a mold. The advance in these molding operations over the past generation has been quite substantial. We have seen not only greatly increased activity but the development of completely new molding technologies. The most striking development has certainly been stretch blow molding which has made plastic beverage bottles an item of everyday life. In traditional blow molding process, melt is extruded vertically downward from an annular die to form a parison. A mold then closes about the parison and air is pumped in. This process is generally applied to high density polyethylene. In stretch blow molding, the parison is fabricated in a separate operation (e.g. by injection molding) from the inflation step. The parison is inflated just above the glass transition temperature. This process has generally been applied to polyethylene terephthalate under conditions in which it will crystallize when the mold is filled.

\section{Kinematics of Mold Filling}

There has been relatively little attention given to the methods in which molds fill despite the obvious importance of the details of filling to the characteristics of the molded parts. The existence of two regimes of flow in mold filling (Fig. 18), a steadily moving front and a shooting jet, had been described by Spencer and Gilmore ${ }^{235)}$ and later investigators ${ }^{236)}$,237) of injection molding. The swirl marks had been noted as blemishes on the surface of molded parts. ${ }^{238), 239)}$ In the mid 1970s, Oda and the author ${ }^{240)}$ made a basic study of the mechanisms of mold filling. They were able to associate the occurrence of jetting with the magnitude of the extrudate swell of the melt exiting the gate into the mold. If the swell $d$ of the jet emerging from the gate was less than the mold thickness $H$, then jetting would occur. This was verified experimentally for a range of isothermal and non-isothermal injection experiments with glass molds.

The kinematics of blow molding processes have received much less attention. Erwin et al. ${ }^{241)}$ have looked at incompletely molded 'short shot' bottles. A more basic approach has been taken by M. Cakmak ${ }^{242)}$ who introduced displacement

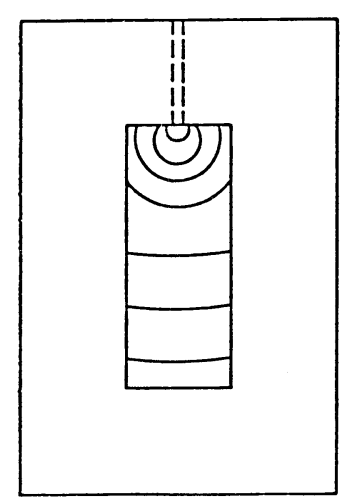

(a)

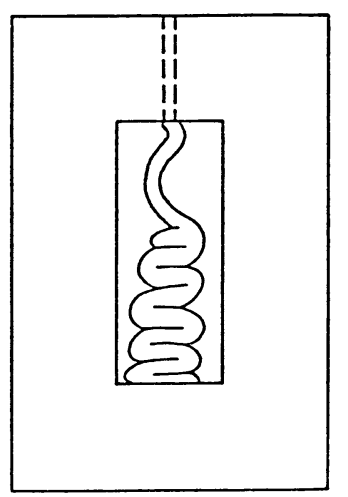

(b)
Fig. 18 Regimes of flow in injection mold filling. 


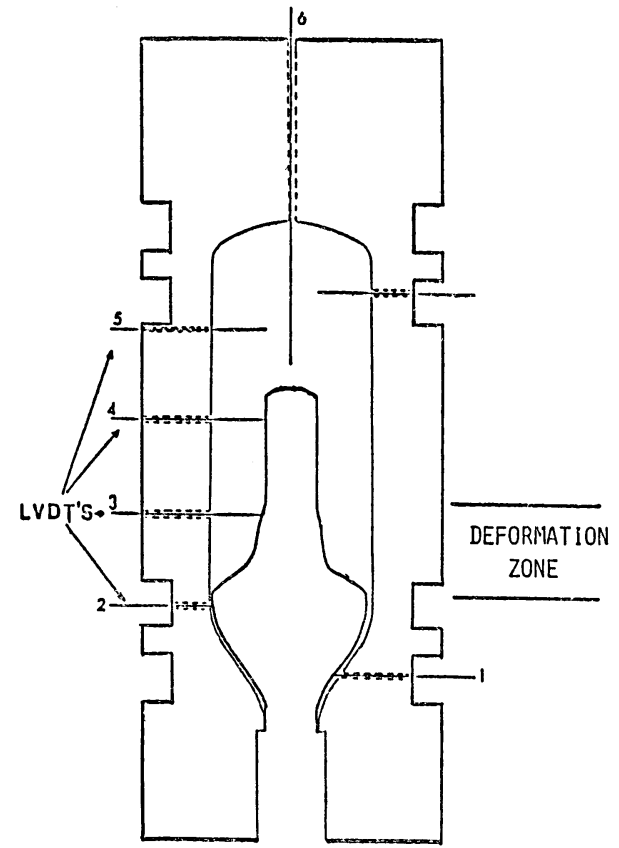

Fig. 19 Mold filling in Corpoplast stretch blow moding process.

transducers into the mold of a Corpoplast Process stretch blow molding machine. It was found that the tubelike parison was not uniformly inflated but inflation generally began in the neck and a 'front' propagated vertically upwards as shown in Fig. 19.

\section{Analysis of Mold Filling}

Analyses of the filling of molds have a long history dating to Spencer and Gilmore ${ }^{235)}$ and Ballman et al. ${ }^{243)}$ However it was only with the work of Richardson ${ }^{244)}$ that sophisticated hydrodynamic modelling capable of the handling of complex molds came to be considered. This author pointed out the application of Hele-Shaw flow theory to this class of problem. This area was the subject of intense activity in the early and mid 1970s. ${ }^{245) ~ 248)}$ The late 1970s and early 1980s saw the development of sophistication computer programs by Austin and his colleagues (Mold flow-Australia), Wang et al. ${ }^{248)}$, Tadmor et al. ${ }^{249)}$ and others to handle complex mold filling problems. This has led this area increasingly into a high level of commercialization and sophistication as major theses of the trend to computer aided design.

\section{Structure Development in Mold Filling}

Studies of the structure of injection molded parts date to the work of Spencer and Gilmore ${ }^{250)}$ and Ballman et al. ${ }^{251)}$ on glassy polystyrene. Ballman et al. presented quantitative birefringence distributions across the cross-section of molded parts, finding orientation maxima near the mold walls and low levels in the center. These activities were extended to crystalline polymers in the 1960s by Yamaguchi and Oyanagi ${ }^{252}$ ) and by Clark ${ }^{253)}$. Predictive studies of birefringences distributions in
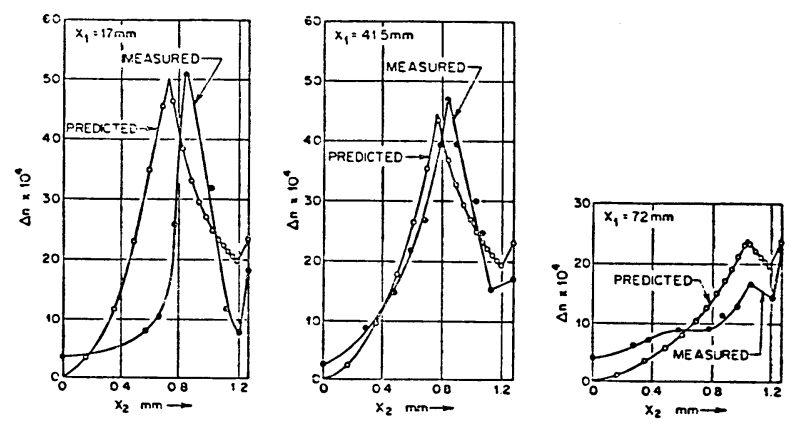

Fig. 20 Predicted and experimental birefringence distributions in injection molded polystyrene bars

molded parts were initiated by Janeschitz-Kriegl ${ }^{254)}$ and by W. Dietz and the author ${ }^{255)}$. These analyses combined hydrodynamic analyses of flow in molds together with Oda et al' hypothesis ${ }^{138)}$ of applying the Rheo-Optical Law to predict birefringence in fabrilated parts. The cooling of the part on the mold and the associated relaxation of stresses and orientation were considered (Fig. 20).

Studies of the structure of injection molded bottles have been rare in the literature. Such a research program was initiated by the author. Investigations with A. Agrawal256) have characterized blow molded polystyrene bottles and with K.J. Choi ${ }^{257)}$ polyethylene bottles. M. Cakmak with Spruiell and the author ${ }^{230,258)}$ made basic investigations of the structure of stretch blow molded polyethylene terephthalate (PET) bottles. Only low levels of orientation are found in traditionally blow molded bottles. White and Agrawal seek to predict these values using a calculation procedure similar to Dietz et al. ${ }^{255}$ ) described above. Stretch blow molded crystalline PET bottles on the other hand have much higher levels of orientation with the chain axis primarily in the circumferential direction and the phenyl groups parallel to the bottle surface. Higher orientation is found using refractometry on inner surface as opposed to the outer surface of the bottles. This apparently results from lower metering temperatures during the inflation process and greater stretch ratios and rates.

\section{MIXING AND TWO PHASE FLOW}

\section{General}

Multiphase flow of polymer melts is an area of continuing and indeed increasingly great technological importance. Mixing of polymers has been studied for more than a century. Blend and multiphase polymer systems have achieved increaing importance over the past generation especially with unique products such as General Electric's Noryl ${ }^{\circledR}$ and Monsanto's Santoprene ${ }^{\mathbb{B}}$. Structured composites formed in the melt such as bicomponent fibers, multilayer sheet and film and molded products have become increasingly important. However the processes all have serious problems associated with them. These are generally associated with the rheological properties 
of the individual polymer melts and their differences.

\section{Stratified Two Phase Flow}

Stratified two phase flow of polymer melts has a long history. There have been intense activities since the 1960 s as we have noted. Major technological developments include multilayer extrusion and bicomponent fibers. The developments of W.J. Schrenk and his coworkers in co-extrusion are largely technological but have rheological aspects. There are complex rheological problems which arise in this area. As first explicitly shown by Southern and Ballman ${ }^{259}$ interface shapes formed during side-by-side coextrusion become distorted when the rheological properties of the two phases are different (Fig. 21). These authors surmised that the effect is due to differences in viscosity and that the low viscosity melt encapsulates the higher viscosity material. This was confirmed by B.L. Lee and the author ${ }^{40)}$ who measured normal stresses as well as the shear viscosity arising in shear flow.

Rheological problems also arise in the injection molding of sequentially injected melts where skin core configurations occur. This process, known as sandwich molding ${ }^{260)}$, was investigated by S.S Young, Y. Oyanagi and the author. ${ }^{261)}$ If the second melt injected has a significantly lower viscosity than the first polymer melt, it will burst through ruining the part. The best

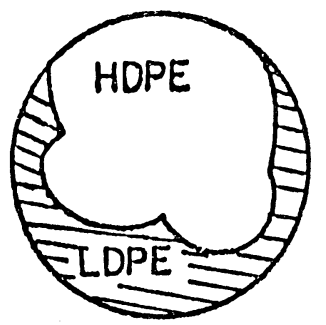

Fig. 21 Cross-sections of extrudates of stratified side-byside polymer melts with different viscosity ratios.

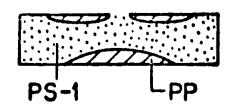

(a) $R^{\circ}=0.04$

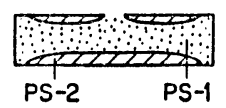

(b) $R^{\circ}=0.08$

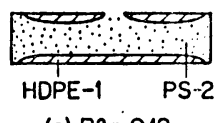

(c) $R^{\circ}=0.12$

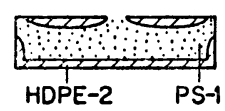

(d) $\mathrm{R}^{\circ}=0.20$

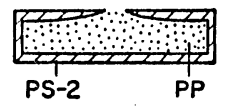

(g) $R^{\circ}=1.77$

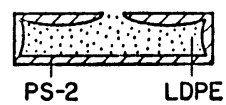

(e) $R^{\circ}=0.40$

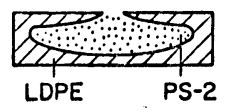

(h) $R^{\circ}=2.52$

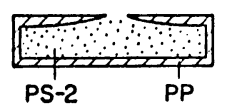

(f) $R^{0}=0.57$

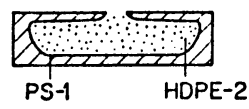

(i) $R^{\circ}=5.00$

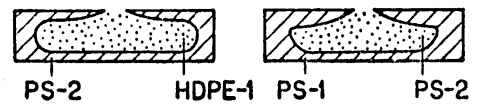

(j) $R^{\bullet}=8.75$ (k) $R^{\circ}=\{3.33$

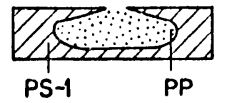

(1) $R^{\circ}=23.60$

Fig. 22 Cross-sections of sandwich molded parts for melt pairs with different viscosity ratios.

results have been achieved when the two melts injected have roughly equal viscosities (Fig. 22).

\section{Flow and Mixing Mechanisms and Internal Mixers}

Surprisingly there have been few basic studies of the phenomena occurring inside of internal mixers. Bergen ${ }^{262)}$ working with various researches (R.E. Gaskell, W. Prager) at Brown University in the 1950s sought to rationally develop an experimental and theoretical science of this area. Bergen's essay, remarkable for its time, fails to see that major attention needed to be given to the rheological characteristics of the materials involved. During the mid 1960s N. Tokita and the author ${ }^{263)}$,264) gave considerable attention to the effects of material characteristics and elastomers and how they effect mixing phenomena. Regimes of flow behavior of elastomers on two roll mills were described. In many materials severe tearing behavior was observed when the melt temperature was lowered. Mixing experiments were carried out and the results interpreted in terms of these flow regimes. These flow regimes should obviously occur in internal mixers as well at low fill factors and in modified form at higher fill factors.

Observations of flow inside of internal mixers are of more recent vintage. A flow visualization experiment on a simple internal mixer was reported by the author with F. Dibachi, Y. Suetsugu and D. Christopher. ${ }^{265)}$ It was only in the late 1970s that Freakley and Wan Idris ${ }^{266)}$ reported flow visualization studies on silicones at room temperature for a model Banbury mixer with a transparent window. More recently K. Min and the author ${ }^{267)}$ have made extensive experiments on commercial synthetics, rubber and plastics at temperatures of $80^{\circ} \mathrm{C}-200^{\circ} \mathrm{C}$. Observations of tearing have been made as well as a stagnant region on the bridge at the base of the mixing chamber. Min is now making both longitudinal and transverse flow visualization studies as well as of the mixing in of carlon black. Min's researchers may well revolutionize the design of internal mixers.

\section{Development of Phase Morphology in Polymer Blends}

The phase morphology is the dominant factor in determining the properties of polymer blend systems. However with the exception of Tsebrenko, Vinogradov and their coworkers ${ }^{268)}$ there seem to be no efforts to quantify these results. Such a program was initiated in the authors laboratory largely by B.R. Liang ${ }^{269)}$ and especially K. Min. ${ }^{270), 271)}$ Liang et al. found that polypropylene dispersed in nylon- 6 would exhibit phase growth when annealed under quiescent conditions. This morphology could be made finer by supplying a shear history. Min et al. made broad and thorough studies of the influence of process history on phase morphology, clearly showing the dominant role of interfacial tension and smallness of the dispersed phase. Experiments were done on polyethylene (of varying molecular weights) with polystyrene, polycarbonate and nylon-6. Arguments were presented that the phase morphology 
was determined by the viscosity ratio and the dimensionless Taylor number 272

$$
\frac{\text { interfacial forces }}{\text { viscous forces }}=\frac{\kappa}{\eta U}=\frac{\kappa}{\eta \gamma R}
$$

It was possible to correlate the fineness of the dispersion with this dimensionless group. ${ }^{277)}$ There studies have been extended more recently with S. Endo, K. Min, T. Kyu and others using polyethylene/polycarbonate with compatibilizing agents.

$\mathrm{Min}^{270)}$ has proposed explaining the rheological properties of polymer melts in shear flow in terms of the phase morphology, using different models as the relative volume loading of the components change. The results presented were promising.

\section{REFERENCES}

1) J.C. Maxwell, Trans. Roy. Soc. Edinburgh, 20, 87 (1853).

2) J.C. Maxwell, Phil. Trans. Roy. Soc., A157, 49 (1867).

3) J.C. Maxwell, Proc. Roy. Soc., 22, 46 (1873).

4) T. Schwedoff, J. de Phys., 8, 341 (1889).

5) T. Schwedoff, J. de Phys., 9, 34 (1890).

6) T. Schwedoff, Phys. Z., 1, 552 (1980).

7) E.C. Bingham, "Fluidity and Plasticity", McGraw-Hill, NY (1922).

8) W. Kuhn and F. Grun, Kolloid Z. 101, 248 (1942).

9) L.R.G. Treloar, Trans. Faraday Soc., 43, 284 (1947).

10) L.R.G. Treloar, Trans. Faraday Soc., 37, 84 (1941).

11) P.H. Hermans and P. Platzek, Kolloid Z., 88, 68 (1939).

12) F.H. Muller, Kolloid Z., 95, 138 (1941).

13) J.J. Hermans, P.H. Hermans, D. Vermaas and A. Weidinger, Rec. Trav. Chim., 65, 427 (1946).

14) I. Williams, Ind. Eng. Chem., 16, 362 (1924).

15) B. Marzetti, Rubber Age NY, 15, 454 (1974).

16) E. Grenquist, Ind. Eng. Chem., 22, 759 (1930).

17) M. Mooney, J. Rheol., 2, 231 (1931).

18) M. Mooney, Ind. Eng. Chem. Anal. Ed., 6, 147 (1934).

19) M. Mooney, Physics, 7, 413 (1936).

20) J.H. Dillon and N. Johnston, Physics, 4, 225 (1933).

21) J.H. Dillon and L.V. Cooper, Rubber Age, 41, 306 (1937).

22) E.C. Bernhardt, Ed., "Processing of Thermoplastic Materials”, Reinhold, NY (1959).

23) J.M. Mckelvey, "Polymer Processing" Wiley, NY (1962).

24) R.L. Ballman, Rheol. Acta, 4, 137 (1965).

25) F.N. Cogswell, Plastics and Polymers, 36, 109 (1968).

26) J. Meissner, Rheol. Acta, 9, 78 (1969).

27) G.V. Vinogradov, B.V. Radushkevich and V.D. Fikham J. Polym. Sci., A-2, 8, 1, 657 (1970).

28) C.D. Denson and R.J. Gallo, Polym. Eng. Sci., 11, 174 (1971).

29) C.D. Denson and D.L. Crady, J. Appl. Polym. Sci., 18, 1611 (1974).

30) T.G. Fox, S. Gratch and E. Loshaek in "Rheology" Vol. 1, Edited by F.R. Eirich, Academic Press, NY(1956).
31) R.S. Porter, M.J.R. Cantow and J.F. Johnson, Proc. 4th Int. Cong. Rheol., 2, 479 (1964).

32) W.W. Graessley, J. Chem. Phys., 47, 1942 (1967) and W.W. Graessley and L. Segal AIChE J., 16, 261 (1976).

33) S. Onogi, T. Masuda, I.Shiga and F.M. Costachuk, Appl. Polym. Symp., 20, 37 (1973).

34) W. Minoshima, J.L. White and J.E. Spruiell, Polym. Eng. Sci., 20, 1166 (1980).

35) H. Yamane and J.L. White, Polym. Eng. Rev., 2, 167 (1982).

36) G.V. Vinogradov and A.Y. Malkin, J. Polym. Sci., A-2, 4, 135 (1966).

37) G.V. Vinogradov and A.Y. Malkin, "Rheology of Polymers", Mir, Moscow. (1980).

38) C.D. Han, K.U. Kim, N. Siskovic and C.R. Huang, J. Appl. Sci., 17, 95 (1973).

39) C.D. Han, Trans. Soc. Rheol., 18, 103 (1974).

40) C.D. Han, "Rheology and Polymer Processing", Academic Press, NY (1976).

41) B.L. Lee and J.L. White, Trans. Soc. Rheol., 18, 467 (1974).

42) J.L. White and A. Kondo, J. Non-Neret. Fluid Mech., 3, 41 (1977).

43) K. Oda, J.L. White and E.S. Clark, Polym. Eng. Sci., 18, 25 (1978).

44) K. Sakamoto and R.S. Porter, J. Polym. Sci., B, 8, 177 (1970).

45) Y. Ide and J.L. White, J. Appl. Polym. Sci., 22, 1061 (1978).

46) Y. Ide and J.L. White, J. Non-Newt. Fluid Mech., 2, 281 (1977); J. Appl. Polym. Sci., 20, 2511 (1976).

47) C. Robinson, Trans. Faraday Soc., 52, 571 (1956).

48) S.L. Kwolek, U.S. Patent 3,671,542 (1972).

49) P.W. Morgan, Macromolecules, 10, 1381 (1977).

50) J. Hermans, J. Colloid Sci., 17, 638 (1962).

51) H. Aoki, J.L. White and J.F. Fellers, J. Appl. Polym. Sci., 23, 2293 (1980).

52) Y. Onogi, J.L. White and J.F. Fellers, J. Polym. Sci. Polym. Phys. Ed., 18, 663 (1980).

53) J. Bheda, J.F. Fellers and J.L. White, Colloid Polym. Sci., 7, 121 (1980).

54) D.N. Lewis, $P h D$ Dissertation, University of Tennessee (in preparation).

55) W.J. Jackson and H.F. Kuhfuss, J. Polym. Sci. Polym. Chem. Ed., 14; U.S. Patent 3,804,805 (1974).

56) W.J. Jackson, Brit, Polym. J., 12, 154 (1980).

57) R.E. Jerman and D.G. Baird, J. Rheol., 25, 275 (1981).

58) K.F. Wissbrun, Brit. Polym. J., 12, 163 (1980).

59) F.N. Cogswell, Paper presented at the 10th Anniversary Meeting of Society of Rheology of Japan (1983).

60) H. Sugiyama, D.N. Lewis, J.L. White and J.F. Fellers, 
J. Appl. Polym. Sci. (in press).

61) K. Shimamura, J.L. White and J.F. Fellers, J. Appl. Polym. Sci., 26, 2165 (1981).

62) S. Suto, J.L. White and J.F. Fellers, Rheol. Acta, 21, 62 (1982).

63) B.R. Liang, J.L. White and J.F. Fellers, unpublished research (1981-2).

64) N.V. Zakharenko, F.S. Tolstukhiwa and G.M. Barteneu, Rubber Chem. Technol, 35, 326 (1962).

65) F.M. Chapman and T.S. Lee, SPE J., 26, (Jan.) 37 (1970).

66) G.V. Vinogradov, A.Y. Malkin, E.P. Plotnikova, O.Y. Sabsai and Nikolayeva, Int. J. Polym. Mat., 2, 1 (1972).

67) J.L. White and J.W. Crowder, J. Appl. Polym. Sci., 18, 1013 (1974).

68) F. Nazem and C.T. Hill, Trans. Soc. Rheol., 18, 87 (1974).

69) Y. Oyanagi and Y. Yamaguchi, J. Soc. Rheol. Japan, 3, 64 (1975).

70) N. Minagawa and J.L. White, J. Appl. Polym. Sci., 20, 501 (1976).

71) Y. Chan, J.L. White and Y. Oyanagi, J. Rheol., 22, 507 (1978).

72) V.M. Lobe and J.L. White, Polym. Eng. Sci., 19, 617 (1979).

73) H. Tanaka and J.L. White, Polym. Eng. Sci., 20, 949 (1980).

74) L. Czarnecki and J.L. White, J. Appl. Polym. Sci., 25, 1217 (1980).

75) J.L. White, L. Czarnecki and H. Tanaka, Rubber Chem. Technol., 53, 823 (1980).

76) B.A. Knutsson, J.L. White and K.A. Abbas, J. Appl. Polym. Sci., 20, 2347 (1981).

77) S. Toki and J.L. White, J. Appl. Polym. Sci., 27, 3171 (1982).

78) S. Montes and J.L. White, Rubber Chem. Technol, 55, 1354 (1982).

79) Y. Suetsugu and J.L. White, J. Appl. Polym. Sci., 28, 1481 (1983).

80) J.G. Oldroyd, Proc. Camb. Phil. Soc., 43, 100, 383 (1947).

81) J.G. Oldroyd, Proc. Roy. Soc., A. 200, 523 (1950).

82) J.L. White and A.B. Metzner, J. Appl. Polym. Sci., 7, 1867 (1963).

83) R.J. Fisher and M. M. Denn, ALChE J. 22, 237 (1976).

84) J.L. White and Y. Ide, J. Appl. Polym. Sci., 22, 3057 (1978).

85) D.C. Bogue, IEC Fundam., 5, 253 (1966).

86) A.S. Lodge, Trans. Faraday Soc., 52, 120 (1956).

87) A.E. Green and R.S. Rivlin, Arch. Rat. Mech. Anal., 1, 1 (1957).
88) B.D. Coleman and W. Noll, Rev. Mod. Phys., 33, 239 (1961).

89) B. Bernstein, E.A. Kearsley and L.J. Zapas, Trans. Soc. Rheol., 7, 391 (1963).

90) L.J. Zapas and T. Craft, J. Res. NBS, 69A, 591 (1965).

91) T.W. Spriggs, J.D. Huppler and R.B. Bird, Trans, Soc. Rheol., 10, (1) 191 (1966); R.B. Bird and P.J. Carreau, Chem. Eng. Sci., 23, 427 (1966).

92) D.C. Bogue and J.L. White, "Engineering Analysis of Non-Newtonian Fluids", NATO Agardograph 144 (1970).

93) P.J. Carreau, Trans. Soc. Rheol., 16, 99 (1972).

94) M.H. Wagner, Rheol. Acta., 15, 136 (1976).

95) I.J. Chen and D.D. Bogue, Trans. Soc. Rheol., 16, 59 (1972).

96) I.J. Chen, G.E. Hagler, L.E. Abbott, D.C. Bogue and J.L. White, Trans. Soc. Rheol., 16, 472 (1972).

97) T. Takaki and D.C. Bogue, J. Appl. Polym. Sci., 19, 419 (1975).

98) K. Hohenemser and W. Prager, ZfAMM, 12, 216 (1932).

99) J.L. White, J. Non-Newt. Fluid Mech., 5, 177 (1979).

100) Y. Suetsugu and J.L. White, J. Non-Nerwt. Fluid Mech., 14, 121 (1984).

101) J.L. White and H. Tanaka, J. Non-Neret. Fluid Mech., 8, 1 (1981).

102) J.L. White and V.M. Lobe, Rheol. Acta, 21, 167 (1982).

103) J.L. White, Rheol. Acta, 20, 381 (1981).

104) J.L. White, J. Non-Nerot. Fluid Mech., 8, 195 (1981).

105) W. Prager and P. Hodge, "Theory of Perfectly Plastic Solids", Wiley, NY (1951).

106) O. Reynolds, Phil. Trans. Roy. Soc., (1883).

107) K. Weissenberg, Proc. 2nd Int. Rheol. Cong. II (1948).

108) W. Philippoff, Trans. Soc. Rheol., 1, 95 (1957).

109) J.L. White, J. Appl. Polym. Sci., 8, 2339 (1964).

110) J.L. White and N. Tokita, J. Appl. Polym. Sci., 11, 321 (1967).

111) A.B. Metzner, J.L. White and M.M. Denn, $A L C h E J$., 12, 863 (1966).

112) A.B. Metzner, J.L. White and M.M. Denn, Chem. Eng. Proc., 62 (12), 81 (1966).

113) M. Reiner, Physics Today, 17 (January) 62 (1964).

114) J.L. White and W. Minoshima, Polym. Eng. Sci., 21, 1113 (1981).

115) M. Yamamoto, Trans. Soc. Rheol., 15, 783 (1971).

116) W. Prager, "Introduction to the Mechanics of Continua", Ginn, Boston (1961).

117) J.L. White and D.C. Huang, J. Non-Neret. Fluid Mech., 9, 223 (1981).

118) R.B. Bird, W.E. Stewart and E.N. Lightfoot, "Transport Phenomena", Wiley, NY (1960).

119) P.H. Hermans, J.J. Hermans, D. Vermaas and A. 
Weidinger, J. Polym. Sci., 3, 1 (1948).

120) R.S. Stein, J. Polym. Sci., 31, 327 (1958).

121) R.J. Roe and W.R. Krigbaum, J. Chem. Phys., 40, 2608 (1964).

122) R.S. Stein, J. Polym. Sci., 31, 335 (1958); J. Appl. Phys., 50, 339 (1961).

123) S. Nomura, H. Kawai, I. Kimura and M. Kagiyama, $J$. Polym. Sci., A-2, 5, 479 (1967).

124) S. Nomura, H. Kawai, I. Kimura and M. Kagiyama, $J$. Polym. Sci., A-2, 8, 383 (1970).

125) H. Kawai, Proc. 5th Int. Rheol. Cong., 1, 97 (1969).

126) R.E. Desper and R.S. Stein, J. Appl. Phys., 37, 3990 (1966).

127) J.L. White and J.E. Spruiell, Polym. Eng. Sci., 21, 859 (1980).

128) L.R.G. Treloar, Trans. Faraday Soc., 43, 277 (1947).

129) R.S. Stein, F.H. Holmes and A.V. Tobolsky, J. Polym. Sci., 14, 443 (1950).

130) D.W. Saunders, Trans. Faraday Soc., 52, 1425 (1956).

131) W. Philippoff, J. Appl. Phys., 27, 984 (1956); and with F.H. Gaskins and J.G. Brodnyan, J. Appl. Phys., 28, 1118 (1957); Trans. Soc. Rheol., 1, 109 (1957).

132) J.N.C. Adamse, H. Janeschitz-Kriegl, J.L. Den Otter and J.L.S. Wales, J. Polym. Sci., A-2, 6, 871 (1968).

133) J.L.S. Wales, Rheol. Acta, 8, 38 (1969).

134) F.H. Gortemaker, M.G. Hansen, B. de Cindio, H.M. Laun and H. Janeschitz-Kriegl, Rheol. Acta, 15, 256 (1976).

135) C.D. Han and L.H. Drexler, J. Appl. Polym. Sci., 17, 2329 (1973).

136) T. Matsumoto and D.C. Bogue, J. Polym. Sci. Polym. Phys. Ed., 15, 1663 (1977).

137) R.S. Stein, J. Appl. Phys., 32, 1280 (1961).

138) K. Oda, J.L. White and E.S. Clark, Polym. Eng. Sci., 18, 53 (1978).

139) A.I. Isayev, Polym. Eng. Sci., 23, 271 (1983).

140) K.J. Choi, J.L. White and J.E. Spruiell, J. Appl. Polym. Sci., 25, 2777 (1980).

141) T. Asada, H. Muramatsu, R. Watanebe and S. Onogi, Macromolecules, 13, 867 (1980); J. Soc. Rheol. Japan, 6, 130 (1978).

142) Y. Onogi, J.L. White and J.F. Fellers, J. Non-Newt. Fluid Mech., 7, 121 (1980).

143) H. Hermann, Polym. Eng. Rev., 2, 227 (1983).

144) P.S. Johnson, Rubber Chem. Technol., 56, 575 (1983).

145) K. Eise, H. Hermann, H. Werner and U. Burkhardt, Adv. Plastics Technol., 1 (2) (1981).

146) Z. Tadmor, L.N. Valsamis, J.C. Yang, P.S. Mehta, G. Duran and J.C. Hinchcliffe, Polym. Eng. Rev., 3, 29 (1983).

147) Z. Tadmor, Polym. Eng. Sci., 6, 185 (1966).
148) Z. Tadmor and I. Klein, "Engineering Principles of Platicating Extrusion”, Von Nostrand, NY (1970).

149) J.P. Tordella, Trans. Soc. Rheol., 1, 203 (1957).

150) P.L. Clegg, in “Rheology of Elastomers", Pergamon (1958).

151) E.B. Bagley and A.M. Birks, J. Appl. Phys., 31, 556 (1960).

152) P. L. Clegg, British Plastics, (Feb) p. 96 (1966).

153) H. Giesekus, Rheol. Acta, 7, 127 (1968).

154) T.F. Ballenger and J.L. White, Appl. Polym. Sci., 25, 1949 (1971).

155) R. Keunings and M.J. Crochet, J. Non-Neret. Fluid Mech., 14, 279 (1984).

156) J.R.A. Pearson, Trans. J. Plast. Inst., 32, 239 (1964).

157) Z. Tadmor and C.G. Gogos, "Principles of Polymer Processing”, Wiley, NY (1979).

158) R.S. Schechter, AIChE J., 495 (1961).

159) J.A. Wheeler and E.H. Wissler, AIChE J., 11, 207 (1965).

160) F. Rothemeyer, Rheol. Acta, 4, 299 (1965).

161) J.L. White and D.C. Huang, Polym. Eng. Sci., 20, 187 (1980).

162) J.L. Erickson, Quart. Appl. Math., 14, 318 (1956).

163) A.E. Green and R.S. Rivlin, Quart. Appl. Math., 14, 299 (1956) ; W.E. Langlois and R.S. Rivlin, Rend Mat., 22, 169 (1963).

164) H. Giesekus, Rheol. Acta, 4, 299 (1965).

165) A.B. Dodson, P. Townsend and K. Walters, Computers Fluids, 2, 317 (1974).

166) E.B. Bagley, J. Appl. Phys., 28, 624 (1957).

167) C.D. Han, M. Charles and W. Philippoff, Trans. Soc. Rheol., 10, 413 (1969).

168) R.S. Spencer and R.E. Dillon, J. Colloid Sci., 3, 163 (1948).

169) R.I. Tanner, J. Polym. Sci., A, 28, 2067 (1970).

170) D.C. Huang and J.L. White, Polym. Eng. Sci., 19, 609 (1979).

171) D.C. Huang and J.L. White, Polym. Eng. Sci., 21, 1101 (1981).

172) R.E. Nickell, R.I. Tanner and B. Caswell, J. Fluid Mech., 65, 189 (1974).

173) K.R. Reddy and R.I. Tanner, J. Rheol., 22, 661 (1978); Comp. Fluids, 6, 83 (1978).

174) M.J. Crochet and R. Keunings, J. Non-Newt. Fluid Mech., 7, 199 (1980) ; 10, 185 (1982).

175) R.S. Spencer and R.S. Dillon, J. Colloid Sci., 4, 241 (1949).

176) J. Tordella, J. Appl. Phys., 27, 954 (1956).

177) J. Tordella, Rheol. Acta, 1, 216 (1958).

178) J. Tordella, J. Appl. Polym. Sci., 7, 215 (1963).

179) A. Rothenberger, D.R. McCoy and M.M. Denn, Trans. 
Soc. Rheol., 17, 259 (1973).

180) C. Ma, J.L. White, F.C. Weissert and K. Min, J.NonNeret. Fluid Mech. (in press)

181) K. Yoshida, B. Budiman, Y. Okayama and T. Kitao, Sen-i-Gakkaishi, 31, T-335 (1975).

182) H. Menendez and J.L. White, Polym. Eng. Sci., 24, 1051 (1984).

183) A. Ziabiacki, "Fundamentals of Fiber Formation", Wiley, NY (1967).

184) A. Ziabiacki, Kolloid Z., 175, 14 (1961).

185) S. Kase and T. Matsuo, J. Polym. Sci., A, 3, 2541 (1965).

186) F.T. Trouton, Proc. Roy Soc., A. 77, 426 (1906).

187) M.M. Denn, C.J.S. Petrie and P. Avenas, AIChE J., 21, 795 (1975).

188) R.J. Fisher and M.M. Denn, AIChE J., 22, 236 (1976).

189) J.L. White and Y. Ide, J. Appl. Polym. Sci., 22, 3057 (1978).

190) J. Shimizu, K. Toriumi and K. Tamai, Sen-i-Gakkaishi, 33, T-208 (1977).

191) C.H. Chen, J.L. White, J.E. Spruiell and B.C. Goswami, Textile Res. J., 53, 44 (1983).

192) A. Bergononi and A.J. DiCresci, Polym. Eng. Sci., 6, 45, 50 (1966).

193) S. Kase, T. Matsuo and Yoshimoto, Sen-i-Kikai-Gakkaishi, 19, T63 (1966).

194) S. Kase, J. Appl. Sci., 18, 3279 (1974).

195) A.J. Ghisse's and J.J. S.M. Ente, "Rheology" Vol. 3, Edited by G. Asterite, G. Marrucci and L. Nicolaus, Plenum, NY (1980).

196) W. Minoshima, J.L. White and J.E. Spruiell, J. Appl. Polym. Sci,. 25, 287 (1980).

197) H. Yamane and J.L. White, Polym. Eng. Sci., 23, 316 (1983).

198) J.R.A. Pearson and M.A. Matovich, IEC Fundam., 20, 169 (1976).

199) Y.T. Shah and J.R.A. Pearson, Polym. Eng. Sci., 12, 219 (1972).

200) Y.T. Shah and J.R.A. Pearson, IEC Fundam., 11, 145, 150 (1972).

201) K. Katayama, T. Amano and Nakamura, Kolloid Z.Z. Polym., 226, 126 (1968).

202) I. Hamana, M. Matsui and S. Kato, Meilland Textil Ber. 4, 382 (1969).

203) M.A. Omotoso, J.L. White and J.F. Fellers, J. Appl. Polym. Sci., 25, 1573 (1980).

204) L.E. Abbot and J.L. White, Appl. Polym. Symp., 20, 247 (1973).

205) J.R. Dees and J.E. Spruiell, J. Appl. Polym. Sci., 18, 1053 (1974).

206) J.L. White, K.C. Dharod and E.S. Clark, J. Appl. Polym. Sci., 18, 2539 (1974).
207) J.E. Spruiell and J.L. White, Polym. Eng. Sci., 15, 660 (1975).

208) H.P. Nadella, H.M. Henson, J.E. Spruiell and J.L. White, J. Appl. Polym. Sci., 21, 3003 (1977).

209) V.C. Bankar, J.E. Spruiell and J.L. White, J. Appl. Polym. Sci., 21, 2341 (1977).

210) M. Danford, J.E. Spruiell and J.L. White, J. Appl. Polym. Sci., 22, 3357 (1978).

211) Y. Wang, M. Cakmak and J.L. White, J. Appl. Polym. Sci. (in press).

212) T. Kitao, K. Yamada, T. Yamazaki and S. Ohya, Sen-iGakkaishi, 28, 61 (1972).

213) T. Kitao, S. Ohya, J. Furukawa and S. Yamashita, J. Polym. Sci. Polym. Phys. Ed., 17, 1091 (1973).

214) J.R.A. Pearson and C.J.S. Petrie, J. Fluid Mech., 40, 1 (1970).

215) T. Kanai and J.L. White, Polym. Eng. Sci.; 24, 1185 (1984).

216) C.D. Han and Park, J. Appl. Polym. Sci., 19, 3277 (1975).

217) M.H. Wagner, Rheol. Acta, 15, 40 (1976).

218) T. Kanai and J.L. White, Polym. Eng. Rev. (in press).

219) C.D. Han and J.Y. Park, J. Appl. Polym. Sci., 19, 3291 (1975).

220) W. Minoshima and J.L. White, in preparation.

221) P.H. Lindenmeyer and S. Lustig, J. Appl. Polym. Sci., 9, 227 (1965).

222) C.R. Desper, J. Appl. Polym. Sci., 13, 169 (1969).

223) W.H. Maddams and J.E. Preedy, J. Appl. Polym. Sci., 22, 2271, 2239 (1978).

224) K.J. Choi, J.E. Spruiell and J.L. White, J. Polym. Sci. Polym. Phys. Ed., 20, 27 (1982).

225) Y. Shimomura, J.E. Spruiell and J.L. White, J. Appl. Polym. Sci., 27, 2663 (1982).

226) N.D. Huck and P.L. Clegg, SPE Trans., 1, 122 (1961).

227) F.C. Stehling, C.S. Speed and L. Westerman, Macromolecules, 14, 698 (1981).

228) H. Ashizawa, J.E. Spruiell and J.L. White, Polym. Eng. Sci., 24, 1035 (1984).

229) K. Matsumoto, J.F. Fellers and J.L. White, J. Appl. Polym. Sci., 26, 85 (1981).

230) M. Cakmak, J.E. Spruiell and J.L. White, Polym. Eng. Sci., 24, 1390 (1984).

231) M. Cakmak, J.E. Spruiell and J.L. White (in preparation).

232) H. Aoki, Y. Onogi, J.L. White and J.F. Fellers, Polym. Eng. Sci., 20, 221 (1980).

233) J.E. Flood, J.L. White and J.F. Fellers, J. Appl. Polym. Sci., 27, 2965 (1982).

234) H. Bodaghi, T. Kitao, J.E. Flood, J.E. Spruiell and J.L. White, Polym. Eng. Sci., 24, 242 (1984). 
235) R.S. Spencer and C.D. Gilmore, J. Colloid Sci., 6, 118 (1951).

236) M.J. Sleeman and C.D. West, Brit. Polym. J., 6, 109 (1974).

237) J.L. White and H.B. Dee, Polym. Eng. Sci., 14, 212 (1974).

238) Y. Yamaguchi, Y. Oyanagi, Y. Sugai and M. Kunitaka, Res. Repts. Kogakuin Univ., 24, 71 (1968).

239) R.L. Ballman, R.L. Kruse and W.P. Taggart, Polym. Eng. Sci., 10, 154 (1970).

240) K. Oda, J.L. White and E.S. Clark, Polym. Eng. Sci., 16, 585 (1976).

241) L. Erwin, M.A. Pollock and H. Gonzalez, Polym. Eng. Sci., 23, 826 (1983).

242) M. Cakmak, J.L. White and J.E. Spruiell, SPE Antec. Tech. Papers, 30, 920 (1984).

243) R.L. Ballman, T. Shusman and H.L. Toor, Mod. Plastics, 37, 105 (Sept. 1959); 37, 115 (Oct. 1959).

244) S. Richardson, J. Fluid Mech., 56, 609 (1972).

245) M.R. Kamal and S. Kenig, Polym. Eng. Sci., 12, 294 (1972).

246) J.L. Berger and C.G. Gogos, Polym. Eng. Sci., 13, 102 (1973).

247) J.L. White, Polym. Eng. Sci., 15, 44 (1975).

248) J.F. Stevenson, Polym. Eng. Sci., 18, 577 (1978); and with A. Galsky, K.K. Wang, I. Chen and D.H. Reber, ibid., 17, 666 (1977).

249) E. Broyer, C. Gutfinger and Z. Tadmor, Trans. Soc. Rheol., 19, 423 (1975).

250) R.S. Spencer and G.D. Gilmore, Mod. Plastics, 27, 97 (Dec. 1950).

251) R.L. Ballman and H.L. Toor, Mod. Plastics, 38, 113 (Oct. 1960).

252) Y. Yamaguchi and Y. Oyanagi, Res. Repts. Kogakuin Univ., 15 (14), 1 (1964)
253) E.S. Clark, $S P E-J, 23$ (7), 46 (1967).

254) H. Janeschitz-Kriegl, Rheol. Acta, 16, 327 (1977).

255) W. Dietz and J.L. White, Rheol. Acta, 17, 676 (1978).

256) J.L. White and A. Agarwal, Polym. Eng. Rev., 1, 267 (1981).

257) K.J. Choi, Ph.D, Dissertation, Univ. of Tennessee, Knoxville, (1983).

258) M. Cakmak, J. E. Spruiell and J.L. White (in preparation).

259) J.H. Southern and R.L. Ballman, Appl. Polym. Symp., 20, 175 (1973).

260) D.F. Oxley and D.G.H. Sandiford, Plast. Polym., 39, 288 (1971).

261) S.S. Young, J.L. White, E.S. Clark and Y. Oyanagi, Polym. Eng. Sci., 20, 798 (1980).

262) J.T. Bergen, in "Processing Thermoplastic Materials", Edited by E.C. Bernhardt, Reinhold, NY (1959).

263) N. Tokita and J.L. White, J. Appl. Polym. Sci., 10, 1011 (1966).

264) J.L. White and N. Tokita, J. Appl. Polym. Sci., 12, 1589 (1968).

265) J.L. White, F. Dibachi, Y. Suetsugu and D.B. Christopher, Polym. Eng. Rev. (in press).

266) J.M. Freakley and Y. Wan Idris, Rubber Chem. Technol., 52, 134 (1979).

267) K. Min, unpublished research (1984).

268) M.V. Tsebrenko, N.M. Rezanova and G.V. Vinogradov, Polym. Eng. Sci., 20, 1023 (1980).

269) B.R. Liang, J.L. White, J.E. Spruiell and B.C. Goswami, J. Appl. Polym. Sci., 28, 2011 (1983).

270) K. Min, J.L. White and J.F. Fellers, J. Appl. Polym. Sci., 29, 2117 (1984).

271) K. Min, J.L. White and J.F. Fellers, Polym. Eng. Sci., 24, 1327 (1984).

272) G.I. Taylor, Proc. Roy. Soc., A. 146, 501 (1934). 